\title{
ORÍGENES Y FUNDACIÓN DEL INSTITUTO GEOLÓGICO DE MÉXICO
}

\author{
Lucero Morelos Rodríguez \\ Instituto de Geología, Universidad Nacional Autónoma de México \\ lunalucerom@yahoo.com.mx \\ José Omar Moncada Maya \\ Instituto de Geografía, Universidad Nacional Autónoma de México \\ acad@igg.unam.mx
}

Recibido: 18 septiembre 2014; Aceptado: 15 julio 2015.

Cómo citar este artículo/Citation: Morelos Rodríguez, Lucero y José Omar Moncada Maya (2015), “Orígenes y fundación del Instituto Geológico de México", Asclepio, 67 (2): p103. doi: http://dx.doi.org/10.3989/asclepio.2015.21

RESUMEN: En este artículo se estudia la creación y los primeros trabajos de la Comisión Geológica Mexicana (1888), que daría paso al Instituto Geológico Nacional en 1891. Su establecimiento replicó el modelo de los Geological Survey, instituciones impulsadas desde las primeras décadas de la centuria en los países más desarrollados económicamente y con vocación expansionista para la búsqueda, evaluación, conocimiento y levantamiento cartográfico de los recursos minerales y geológicos por manos expertas.

PALABRAS CLAVE: Comisión Geológica Mexicana; Instituto Geológico de México; Secretaría de Fomento; México; Porfiriato; Siglo XIX.

\section{THE ORIGINS AND FOUNDATION OF THE GEOLOGICAL INSTITUTE OF MEXICO}

ABSTRACT: This article aims for the creation and early works of the Mexican Geological Commission (1888), antecedent the Geological Institute of Mexico in 1891. Its establishment said the model of the Geological Survey, institutions created since the early decades of the century in more developed economically and expansionist vocation for searching, prospecting, survey and mapping of mineral and geological resources by experts.

KEY WORDS: Mexican Geological Commission; Geological Institute of Mexico; Geological Survey; Deparment of Fomento; Mexico; Porfiriato; 19th Century.

Copyright: $\odot 2015$ CSIC. Este es un artículo de acceso abierto distribuido bajo los términos de la licencia Creative Commons Attribution-Non Commercial (by-nc) Spain 3.0. 


\section{INTRODUCCIÓN}

En 1901, el célebre geólogo y paleontólogo alemán Karl von Zittel (1839-1904) indicaba que la edad heroica de la geología se ubicaba entre 1790 a 1820 . Este periodo se caracterizó por el significativo desarrollo de las ciencias químicas, la historia natural y la configuracion de nuevas especialidades, entre ellas la geología; también por el avance de los métodos empíricos que se complementaban con los fundamentos teóricos para explicar el origen de los minerales y la tierra por medio de la doctrina acuosa, del calor interno o el catastrofismo (Zittel, 1901). Sugiere Bowler (1998) que en este lapso se atestiguó «la elaboración de un bosquejo completo de la historia de la Tierra donde la superficie entera quedó sometida al escrutinio científico».

El avance en estos conocimientos derivó en la iniciativa de las monarquías europeas modernizadoras para aprovecharlos para la instrucción de funcionarios y técnicos destinados a la explotación y dirección de las labores mineras, por medio de la fundación de Academias de Minas (Brianta, 2000).

Estas instituciones fueron creadas en Europa en la segunda mitad del siglo XVIII: Freiberg, Sajonia (1765), Banska Stiavnica en Austria (1770) y Almadén, España (1777). En América el modelo alemán se replicó con la fundación del Real Seminario de Minería de México en 1792 (Izquierdo, 1958). Para la historiadora Ursula Klein (2012), los graduados de las Academias de Minas representaron un nuevo actor, un "artisanal-scientific-expert», es decir, ingenieros científicos instruidos en la metalurgia, química, orictognosia o mineralogía, geognosia o geología y en la explotación de minas, capaces de hacer acopio de minerales, rocas, fósiles y meteoritos, profundizar en los aspectos geológicos y legales de los lugares visitados y levantar mapas.

La institución pionera fue dirigida por Abraham Gottlob Werner (1749-1817), considerado uno de los pilares fundamentales de la geología moderna, creador del sistema de descripción mineral por caracteres exteriores, de la teoría que explicaba el origen de los minerales conocida como Neptunismo y estimado entre sus contemporáneos como «el gran oráculo de la ciencias de la Tierra» (Hallam, 2008; Pelayo, 2001). Varios de los personajes relevantes en las ciencias geológicas fueron sus alumnos.

De particular interés para América son Fausto de Elhúyar (1785-1833), Andrés Manuel del Río (17641849), Friedrich Traugott Sonneschmidt (1763-1824), Alexander von Humboldt (1769-1859), y varios inge- nieros expertos, también egresados de la academia de minas sajona, entre los que destacaron Friedrick von Gerolt (1797-1879), Carl de Berghes (1782-1869) ${ }^{1}$, Joseph Burkart (1798-1870), Federico Weidner e Ignacy Domeyko (1802-1889), quienes visitaron el territorio en diferentes momentos y por diversas circunstancias, y estuvieron vinculados al desarrollo de las ciencias geologicas en México a través de la red de intercambios epistolares y factuales que tejieron con las elites científicas novohispana y mexicana (Mentz, Radkau, Scharrer, Turner, 1982; Escamilla, 2005; Uribe, 2006; Wehrheim, 2010; Morelos, 2014).

Fue en el Real Seminario de Minería donde germinaron las comisiones geológicas que dotaron de infraestructura y sueldos a los ingenieros de minas que transitarían a geólogos estatales (Lundgreen, 1990). Sus aportes al conocimiento de los recursos minerales del país pueden estimarse por los numerosos textos e informes desarrollados y por la importante labor en la representación gráfica del territorio, primero a nivel local, después a nivel regional y, finalmente, en un gran proyecto de construir la carta geológica de la República por una nueva institución: la Comisión Geológica Mexicana (1888), precursora del Instituto Geológico Nacional (1891).

En el presente texto se busca hacer un recorrido por las representaciones gráficas de la geología en México elaboradas desde comienzos del siglo XIX por hombres de ciencia, viajeros, ingenieros, militares mexicanos y extranjeros, que aportaron información relevante para el conocimiento de las riquezas minerales y geológicas del país y que sirvieron de sustento para la construcción de los primeros mapas minero y geológico generales de la República Mexicana en 1889 que debían exhibirse en la Exposición Universal de París de ese año; y también mostrar los derroteros que siguieron los geólogos oficiales para lograr su cometido.

\section{EL SURGIMIENTO DE LA GEOLOGÍA Y LA EXPLORA- CIÓN DEL TERRITORIO MEXICANO EN EL SIGLO XIX}

México es heredero de una práctica ancestral que se emparenta con una tradición científica de «hurgar en la tierra» en búsqueda de minerales, piedras preciosas, petróleo, fósiles, materiales de construcción, etc., que se remonta al menos 500 años atrás. La relevancia de la industria extractiva ha sido tal que, desde su nacimiento como nación independiente, los diferentes grupos políticos gobernantes buscaron y ensayaron distintas alternativas de riqueza que fijaron como fundamento el patrimonio depositado en 
un suelo pródigo en minerales. Esta búsqueda estuvo relacionada con el desarrollo de la minería académica, en la que concurrieron varios saberes, entre ellos la geologia, y cuya utilidad inspiró la creación de instancias para la instrucción científico-técnica, la exploración y la explotación de los recursos naturales.

Desde el siglo XVI México se había posicionado como el principal productor de plata en el mundo, aunque las primeras décadas de vida independiente transcurrieron en medio de continuas guerras entre los distintos grupos políticos, intervenciones, invasiones y la pérdida de más de la mitad del territorio nacional. A partir de 1860, la actividad minera alcanzó un desarrollo importante mediante la diversificación de minerales de uso industrial; derivado de ese interés llegaron del extranjero diversas comisiones de exploración científica con la idea de estudiar e invertir en los recursos no renovables; asimismo, este crecimiento inspiró también a empresarios y al gobierno mexicano (Velasco, Flores Clair, Parra, Gutiérrez, 1988).

Durante el porfiriato (1876-1910) el escenario se presentó más viable para el despegue económico. Fue un periodo caracterizado por un clima de relativa paz, de impulso al fomento gubernamental, que corrió en paralelo a la instrucción formal, lo que hizo posible la consolidación de una unidad legislativa, el tendido de caminos de fierro, la política de "puertas abiertas» a los inversionistas extranjeros y la centralidad en las instituciones educativas.

Especial interés reviste el Real Seminario de Minería, después Colegio de Minería (1821) y Escuela Nacional de Ingenieros (1867), toda vez que algunos de sus profesores, alumnos y egresados fueron los pioneros de la geología en México y formaron parte de las numerosas comisiones científicas y de exploración organizadas desde la segunda mitad del siglo XIX por la Secretaría de Fomento, Colonización e Industria (Bernstein, 1964; González et al., 1994). Lo anterior puso en evidencia que durante el último tercio del siglo, se experimentó el funcionamiento recíproco entre la práctica del sistema educativo y la política económica de reconocimiento territorial y de exploración de los recursos naturales. Con las riquezas depositadas en el subsuelo, el estímulo del gobierno federal y la cooperación del gobierno local, se auguraba el éxito².

Un punto de partida lo representa la creación del Importante Cuerpo de la Minería de Nueva España, institución que comprendía al Real Tribunal de Minería y al Real Seminario de Minería o Colegio Metálico. Esta escuela abrió sus puertas el 1ㅇ de enero de 1792 bajo la dirección del mineralogista Fausto de Elhúyar para la formacion de un cuerpo científico técnico encargado de la dirección y explotación minera (Ramírez, 1890; Izquierdo, 1958; Flores Clair, 2000).

En este espacio se ubica el inicio del proceso institucional de las ciencias geológicas en México con la creación de la cátedra de orictognosia, geognosia y arte de minas, el 27 de abril de 1795 por Andrés Manuel del Río. Este profesor fue el autor del primer libro de texto para la enseñanza facturado en el continente que llevó por título: Elementos de Orictognosia o el conocimiento de los fósiles (1795), basado en la clasificación mineralógica de caracteres externos de Werner. Una segunda parte de esta obra se imprimó en 1805 (Escamilla, 2011; Rubinovich, 1992; Uribe, 2013).

En esta última edición se integró la Pasigrafía geognóstica de Alexander von Humbolt, obra que «dotó de un lenguaje universal a las cartas y permitió de manera clara la representación de datos geológicos y cartográficos, por medio de letras, flechas, símbolos y abreviaturas para las formaciones y tipos de rocas» (Moncada, 2003). Asimismo, este volumen estuvo acompañado de dos cortes geológicos que indicaban la superposición de las rocas en ambos continentes.

La obra del barón prusiano influenció e inspiró a numerosos viajeros y científicos extranjeros y nacionales que contribuyeron al estudio y a la representación gráfica de la geología mexicana, entre ellos destacan los trabajos del diplomático e ingeniero alemán Frederick von Gerolt, los ingenieros Carl de Berghes y Joseph Burkart, el botánico y geólogo Henri Guillaume Galeotti (1814-1858) y el explorador galo Eugéne Saint Clair Duport (1804-1882).

Galeotti publicó «Viaje al Cofre de Perote», así como la «Noticia geológica de los alrededores de San José del Oro» (1838), acompañada de la Carte géognostique des environs de Zimapan au Mexique, el Coup d'Oeil sur la Laguna de Chapala, avec des Notes Géognostiques y en coautoría con Henri Nyst (1813-1880) la «Notice sur le Calcaire Cretacé des environs de Jalapa au Mexique» de 1839 (Aguilar y Santillán, 1908).

Por su parte el baron Frederick Wilhelm von Egloffstein (1824-1885) publicó el libro Contributions to the Geology and the Physical Geography of Mexico including a Geological and Topographical Map with Profiles, of some of the principal Mining Districts, together with a graphic description of an ascent the Volcano Popocatepetl (1864)3 ${ }^{3}$ obra que integró el Geological Map and Profiles of some of the princi- 
pal Mining Districts of Mexico de Gerolt (Egloffstein 1864; Marcou, Belknap, 1884; Aguilar y Santillán, 1908; Rowan, 2012).

Correspondió al mineralogista y agente de la Compañía Alemana de Minas, Friedrick von Gerolt ${ }^{4} \mathrm{y}$ al ingeniero mecánico de la misma, Carl de Berghes el levantamiento de la Carta Geognóstica de los principales Distritos Minerales del Estado de México de 1827, valorada como el primer mapa geológico del México Independiente impreso a color, que incluyó las elevaciones de los principales puntos sobre el mar en pies ingleses y la explicación de las haciendas de labor y de beneficio, rancherias, ojos de agua termales, distritos minerales, minas de oro, plata, cobre, fierro y plomo y una gama a colores que indicaba las principales formaciones de rocas (Gerolt, 1828).

Joseph Burkart (1798-1870), ingeniero alemán residente en México entre 1825 a 1834, arribó al país para ocupar el cargo de director de la compañía minera de Tlalpujahua y más tarde de Veta Grande. Elaboró varios estudios sobre la explotación minera, la geología mexicana y confeccionó dos importantes cartas geológico-mineras, el Geognostische Skizze des Weges von Tlalpuhajua nach Huetamo dem Jorullo und Valladolid. Maastab von 20 leguas 26.63 aufeinen Grad (Esbozo geognóstico de los caminos de Tlalpujahua a Huetamo, Jorullo y Valladolid) en 1832 (Ramírez, 1875; Corona, Uribe, 2009).

Cuatro años después, Burkart levantó el Mapa de las montañas de Zacatecas (Karte des Gebirges von Zacatecas). Ambas cartas fueron integradas en su obra Aufenthal und Reisen in Mexico in den Jahren 1825 bis 1834, de dos volúmenes publicada en 1836 en Stuttgart y dedicada al barón de Humboldt, la cual contenía noticias diversas sobre el país, sus productos, el desarrollo de la ciencias, la importancia del conocimiento de las rocas, el estudio de los ópalos, sus brechas, los metales preciosos y la historia de las explotaciones. Además este experto agregó y corrigió datos mineralógicos y petrográficos aportados por Humboldt y Gerolt y mantuvo a lo largo de su vida un sólido intercambio epistolar y de objetos científicos con el mexicano Antonio del CastiIlo (1820-1895) (Burkart, 1836; Maldonado, 1952; Mentz, 1980; Morelos, 2014).

Del Castillo (Figura 1) fue sucesor de Andrés del Río en la cátedra de mineralogía en el Colegio de Minería en 1846 y un ferviente promotor de la formación científico-técnica y práctica de los ingenieros de minas, toda vez que consideraba que esos profesionales no podían carecer de los conocimientos esenciales para el levantamiento de planos topográficos, geognósticos y petrográficos, de la geometría descriptiva por sus amplias aplicaciones a los planos petrográficos, los procedimientos del beneficio de metales, «donde los conocimientos de metalurgia y química tienen su aplicación» y, agregó:

la precedente enumeración rápida de las ciencias que desde luego tienen una aplicación inmediata y directa en la práctica de minas, son a mi ver las que forman el criterio y tópicos del buen ingeniero de minas. Mas como resumen de su vasto saber, la geología viene a formar el último término de su larga y penosa carrera científica. En fin, nosotros no podemos mas que emitir nuestros sinceros votos por el progreso de las ciencias industriales, como base de la prosperidad de las naciones (Castillo, 1843).

Figura 1. Ingeniero Antonio del Castillo (1820-1895)

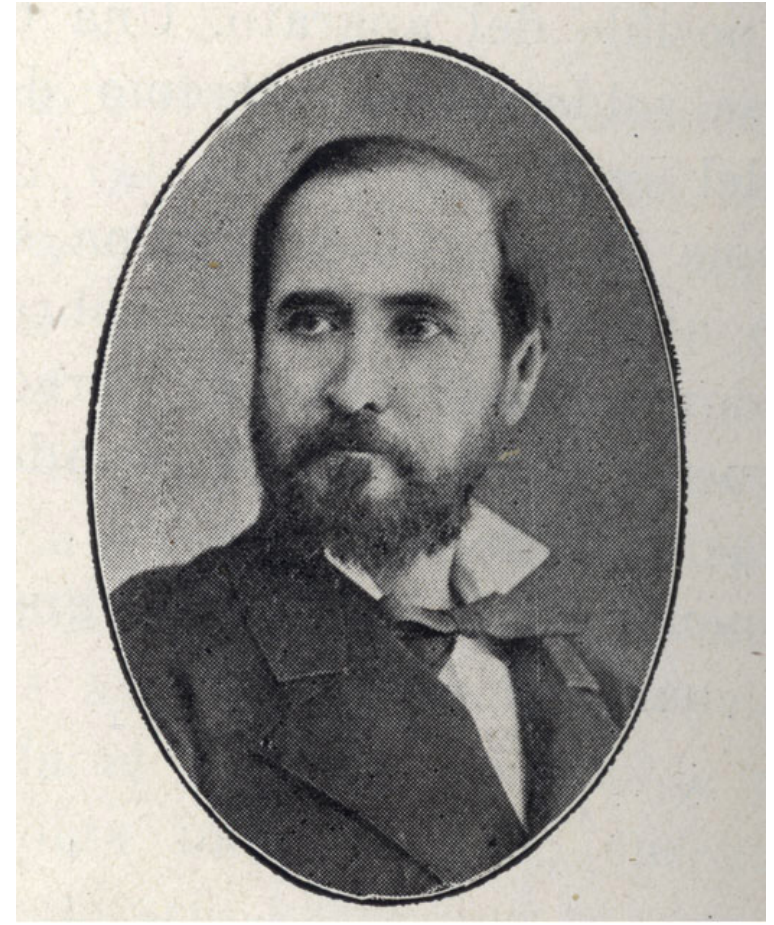

Fuente: Salazar, 1923.

De estas fechas destaca el reconocimiento territorial en el Istmo de Tehuantepec relizado en 1842 por la Comisión Exploradora del Istmo de Tehuantepec, impulsada por José de Garay y sufragada por el gobierno de Antonio López de Santa Anna para estudiar la factibilidad de abrir una vía de comunicación 
interoceánica (Garay, 1844; Moro, 1844; Fernández, 1878; García de León, 1993).

En este tenor se ubica el Plano geológico de una Parte Austral del Istmo de Tehuantepec de 1843, que acompañó a la descripción geológica de la zona realizada por Andrés Manuel del Río y Manuel Robles como parte de la Memoria sobre el proyecto interoceánico en el Istmo de Tehuantepec (Moro, 1844). Años más tarde, el ingeniero Agustín Barroso contribuiría con la Carta geológica del istmo de Tehuantepec formada por la Comisión Mexicana que exploró el Istmo el Año de 1871, bajo la dirección del ingeniero Manuel Fernández Leal, a escala 1: 500000 y litografiada por Hipólito Salazar, así como el Geological map of the Isthmus of Tehuantepec (1871) del cirujano y geólogo naturalista John Crawford Spear (1838-1908), integrante de la expedición de la marina estadunidense a cargo del capitán Robert Wilson Shufeldt (1822-1895), autor de Reports of explorations and survey. En el mapa destaca la gama de colores que indican la litología de la región y las noticias sobre manifestaciones de petróleo (Shufeldt, 1872; Fernández, 1879; Blanco, Moncada, 2011).

En términos administrativos también surgieron instancias de importancia capital que buscaron articular la política económica con el estudio de la naturaleza y geografía mexicana. Entre las más importante se sitúa el Ministerio de Fomento, fundado en 1853, dependencia especial que tuvo bajo su cargo el avance de las industrias y su conexión con las ciencias.

Numerosos ingenieros científicos integraron las comisiones especiales y expediciones científicas organizadas por las corporaciones y por el aparato gubernamental. Destacan así para el caso que nos atañe, la factura de productos científicos novedodos que realizaron sobre los temblores, sismos, fenómenos geológicos, levantamiento de cartas, perfiles y planos para el trazo del ferrocarril, la estadística, la minería y la geología. En estas empresas elaboraron informes y valiosas memorias que contienen aspectos históricos del lugar estudiado, consideraciones sobre el origen de la tierra, la cronología geológica, el cauce de su ríos, manantiales, lagos, mantos acuíferos, la flora, la agricultura, el tipo de suelos, la constitución geológica, el tipo de rocas en relación a la explotación minera, las principales elevaciones, islas, pozos brotantes (ascendentes o artesianos), volcanes, grutas, cuevas y cavernas.

Por su parte el ingeniero aleman Federico Weidner, avencidado en México aparentemente desde 1850, elaboró ocho años después de su llegada el informe solicitado por el gobernador de Durango José de la Bárcena, que llevó por título, El Cerro de Mercado de Durango o compendio de noticias mineralógicas, geognósticas, históricas, estadísticas, y metalúrgicas del dicho cerro y la ferrería de San Francisco, el cual estaba acompañado de un mapa geognóstico de esa montaña que ofrecía una «idea de su configuración, orígen y relaciones con los cerros que lo rodean», una colección de fósiles, ordenados según sus caracteres mineralógicos y marcados con los número del 1 al 50, así como dos alhajas con piedras preciosas procedentes de esa cumbre (Weidner, 1858).

Por orden del gobernador de Sinaloa Plácido Vega, Weidner levantó la carta general de ese estado, obra que fue publicada por Joaquín de Mier y Terán, ministro de Fomento en 1868 (Olea, 1975; Ibarra, Ruelas, Carrillo,1994). También levantó el Plano topográfico de la ciudad de Culiacán, el más antiguo hasta hoy conocido, durante su visita a esa comarca en los meses de agosto y septiembre de 1861 por la Comisión Científica de Geografía, Estadística y de Deslinde de tierras de la que el ingeniero era jefe. Sin embargo, la invasion francesa en el estado dio por terminadas los actividades (Orozco, 1871, 1881). En 1882 imprimió en San Francisco una carta litografiada del estado de Sinaloa bajo el título Map of the State of Sinaloa, Mexico, from actual Surveys and reconnoissances, a escala 1:660,000. Este mapa es el primero que contiene la división en distritos de ese estado, cuestiones geográficas, geológicas y de su naturaleza (Weidner 1882, 1884).

Destacan también los aportes hechos por Auguste Dollfus, Eugène de Montserrat, Paul Pavie, Guillemin Tarayre, de manera particular los elaborados para la Commission Scientifique du Mexique que dejaron "una obra de la mejor calidad" y su impronta en la práctica geológica (Maldonado, 1964; Soberanis, 1995). Así como los propios hombres de ciencia mexicanos: Justo Gómez de la Cortina (1799-1860), Leopoldo Río de la Loza (1807-1876), los ingenieros José Ma. Bustamante, Agustín Barroso, Juan N. Cuatáparo (ca. 1843-1882), Santiago Ramírez (1836-1922), Mariano Bárcena (1841-1899), Pedro López Monroy y Próspero Goyzueta (1825-1889).

El ingeniero Goyzueta fue delegado para realizar el plano y la memoria de la geología como parte de la Comisión de la Carta Hidrográfica y Geológica del Valle de México en 1861, bajo la dirección del ingeniero Francisco Díaz Covarrubias (1833-1889) (Orozco, $1864)^{5}$. En esta fecha el director del Colegio de Mi- 
nería, el ingeniero José Salazar Ilarregui (1823-1892) formuló un plan de trabajo «que entrañaba la solución de variadas cuestiones geológicas» por medio del conocimiento de los distritos de minas «bajo todas sus fases" y el cual se ejecutaría durante las prácticas de campo. Con su elaboración se determinaría el enlace geográfico de los distritos y el estudio de los criaderos metalíferos para obtener una clasificación de los sistemas de vetas (Robles, 1866). Para el cometido se formarían dos comisiones, una para Pachuca y otra para Guanajuato. Sin embargo, dada la escasez financiera que atravesaba el erario tras la Guerrra de Tres Años (1857-1861) solamente se formó la primera a cargo de Del Castillo.

En el plan de Pachuca, el ingeniero efectuó el estudio de un gran número de datos existentes en la Escuela Práctica de esa ciudad, formó colecciones geognósticas y paleontológicas dispuestas y arregladas en el gabinete de geología. Además, celebró un contrato con la Secretaría de Fomento en el que se comprometía a concluir las cartas y memorias geológicas que darían a conocer la formación geológica de los distritos de minas y su riqueza minera, en su variedad de especies metálicas, sales, combustible mineral y demás materiales para la industria. Sin embargo, en 1863 se interrumpió el proyecto y la Escuela cerró sus puertas tras la intervención francesa.

Durante el Segundo Imperio vieron su continuidad las empresas de reconocimiento territorial y la reforma al ramo minero. En esta tesitura, para Del Castillo era necesario preparar la carta geológica de la cual se carecía. Para su realización era esencial la colecta de materiales, el adiestramiento de trabajadores que debieran ocuparse de ella y arreglar, preparar y clasificar las colecciones mineralógicas, geológicas y paleontológicas que establecimientos como el Museo Nacional y la Escuela Imperial de Minas resguardaban. La carta, aducía Castillo (1870), además de ser un «monumento a la ciencia nacional», representaba un quehacer de utilidad pública, tanto por el desarrollo de la ciencia misma como por la necesidad de tener un conocimiento más acabado de la riqueza mineral.

Fue así que Del Castillo propuso a Luis Robles Pezuela, ministro de Fomento, la formación de la Carta Geológica de los distritos minerales del Real del Monte, Pachuca, El Chico, Capula, Santa Ana, Santa Rosa Tepenené; la de Guanajuato con los distritos que se comprenden en la carta del capitán James Vetch (1789-1869), quien fuera director de la Compañía in- glesa de Real del Monte; la de Zacatecas, que incluiría a esa ciudad y el distrito de Veta Grande, la de los distritos de Fresnillo y Plateros y la del Valle de México para enlazarla con la serranía del Real del Monte. Las cartas serían acompañadas de memorias explicativas de los detalles, con la descripción mineralógica de cada distrito; la que se completaría y clasificaría en el orden definitivo que resultara del conjunto de los trabajos. Además, todas las colecciones recogidas serían enviadas a la Escuela de Minas.

El programa de trabajo, que estaba planeado para diez y ocho meses, no se llevó a efecto porque a Del Castillo le fueron encomendadas otras tareas, como los comentarios y reformas a las Ordenanzas de Minería pero sobre todo, por el estado de guerra entre las fuerzas republicanas e imperialistas (Ramírez, 1890).

En 1867, con el triunfo del gobierno mexicano sobre los imperialistas, la Escuela Imperial de Minas se transformó en Escuela Nacional de Ingenieros (ídem). En esta institución, el profesor Del Castillo se consagró como titular en la cátedra de Mineralogía, Geología y Paleontología, la cual desempeñaría hasta 1895, año de su muerte. Sus cursos se distinguieron por una nueva forma de enseñar la ciencia geológica, ya que en las prácticas de campo «acostumbraba llevar a sus alumnos a distintas partes del país con el fin de adquirir datos para la formación de una carta geológica de la República y colectar ejemplares de rocas y minerales» para enriquecer los museos o gabinetes de la Escuela Minería, del Museo Nacional y la suya propia (Aguilera, 1896).

Varias de estas aportaciones respondieron a las empresas de reconocimiento científico organizadas por las compañías de capital extranjero y la Secretaría de Fomento bajo los regímenes republicano e imperial, por los gobiernos estatales, como la Comisión para formar la Carta Geológica del Estado de México en 1874, a cargo de los ingenieros de minas Juan N. Cuatáparo y Santiago Ramírez (1836-1922), la cual representó el primer geological survey mexicano y por la Sociedad Mexicana de Historia Natural fundada en 1868, cuyo primer presidente fue el propio Del Castillo.

Este ingeniero, mejor posicionado en las elites científica y política republicanas, impulsó y promovió la consolidación institucional de la geología cuando la enseñanza y la certificación de los ingenieros científicos se hizo evidente, fundando la Comisión Geológica y después el Instituto Geológico Nacional, del que fue su primer director. Estas instituciones inyectaron un gran dinamismo intelectual sobre la riqueza geológica 
del país que permitieron el nacimiento de las primeras descripciones geológicas modernas de varias regiones así como de mapas relativos a varios aspectos geológicos.

Durante el porfiriato se articularon los mecanismos para el despegue económico, la sanidad en el fisco, la política diplomática, la apertura económica a capitales extranjeros para las inversiones, la uniformidad legislativa, comercial y fiscal, la injerencia estatal en la localización de las riquezas naturales y en la enseñanza media y superior, que derivó en la centralización de un Estado nacional fuerte.

Fue un periodo de auge de la actividad científica que se tradujo en la formación de sociedades especializadas, la multiplicación de publicaciones, el surgimiento y fortalecimiento de las primeras instituciones de investigación y con ellas la designación de los hombres de ciencia dentro de estos espacios, cuyo estímulo radicó en ofrecer explicaciones de los fenómenos físicos y participar en proyectos de escala internacional encaminados al estudio de la naturaleza y sus recursos, interés que corrió paralelo a las empresas y corporaciones científicas y económicas de origen europeo, norteamericano y nacionales (Barnes, 1987; Saldaña, Azuela, 1996; Azuela, Guevara, 1998; Villegas, 2005).

Entre 1881 y 1891, la administración del general Carlos Pacheco (1839-1891) al frente de la Secretaría de Fomento se caracterizó por la introducción de una serie de innovaciones orientadas a la industrializacion del país, entre ellas la creación de la Sección $4^{\text {a }}$ de "Agricultura y Minería», el control de la escuelas nacionales de estos ramos, la organización de corporaciones y comisiones de exploración temporales, la contratación de ingenieros para su desempeño, el apoyo para la fundación en 1882 del Instituto Geológico en la Escuela Nacional de Ingenieros y la petición que hiciera al Congreso de la Unión en 1886 y 1888 para su establecimiento (Morelos, 2014).

\section{TENTATIVAS PARA LA FUNDACIÓN DEL INSTITUTO GEOLÓGICO (1882-1886)}

Diversas voces de la elite científica manifestaron la necesidad de crear comisiones para la exploración y el inventario de los recursos, por ejemplo, el ingeniero Pedro López Monroy (1878) advertía que de hacerse, «el fisco federal no tardaría en sentir benéfica influencia», toda vez que "las naciones más cultas invierten sumas considerables, y envían numerosas comisiones para la exploración de regiones conocidas y lejanas».
A tono con la política exploratoria de la Secretaría de Fomento, desde comienzos del decenio de 1880 la dependencia organizó empresas científicas en búsqueda de noticias de "la riqueza mineral latente del país», cuyo dominio pertenecía a la nación, para la explotación con fines comerciales de los yacimientos minerales, de carbón de piedra, bitúmenes y petróleo, pues la demanda del combustible fósil era imperiosa y con su ubicación se buscaba mitigar la destrucción de los bosques (Castillo, 1868; Dublán, 1878, 1898).

En este tenor se organizaron numerosas comisiones de corte temporal a lo largo y ancho del territorio mexicano con el fin de integrar un inventario y realizar la evaluación de los recursos para su exportación. Sin embargo, se lamentaba el desconocimiento territorial y la falta de cartas geológicas y mineras de diversas regiones (Blanco, Moncada, 2011; Morelos, 2012).

Como se refirió líneas arriba, la petición más temprana que hemos encontrado sobre la fundación de un Instituto Geológico Nacional data de 1882, cuando el ingeniero Antonio del Castillo se desempeñaba como director de la Escuela Nacional de Ingenieros y catedrático de mineralogía, geología y paleontología y química. El proyecto descansaba en el argumento de que la geología y sus ramas avanzaban con creces las que «manifestarán la utilidad y harán que se cultiven con más afán estas ciencias, fuente de riqueza de las naciones, que hasta ahora se han mirado por la generalidad con indiferencia», a pesar de su directa conexión con los servicios que hiciera a la industria (AHPM,1882/ IV/ 218/ doc. 1, f. 1; doc. 26, f. 2).

En mayo de 1882, Del Castillo envió un memorándum a su amigo el general Carlos Pacheco en el que le anunciaba que "ya existen en los salones de la casa de la Dirección de Minería, todos los materiales reunidos y ordenados, es decir, las grandes colecciones de rocas, de fósiles y de minerales; planos, perfiles y acopio de fotografías; de dibujos y de litografías de los fósiles animales o vegetales, que se han encontrado hasta ahora y que representan la paleontología mexicana; así como su flora fósil que ha producido el carbón de piedra» (AHPM, 1882/ IV/ 218/ doc. 1, fs. 3-4).

Las actividades proyectadas en un inicio por el ingeniero Antonio del Castillo estarían abocadas de manera esencial a la construcción de mapas que ofrecerían una idea más fidedigna de los filones minerales, la antigüedad de las rocas y su tipo, así como su distribución en la geografía nacional. Para la construcción de estos productos era imprescindible la organización de expediciones al campo y de estudios de gabinete, 
ambos de visos científicos e industriales. Con el acopio de esos materiales se realizarían el bosquejo de la Carta general geológica de la República, cartas mineras geológicas de los más importantes minerales o distritos minerales del país, una carta carbonífera de la República, cortes geológicos longitudinal y transversal de todo el territorio de la República, una memoria sobre la estadística mineral del país y un atlas de la paleontología mexicana.

Estos productos estaban orientados a conocer la «riqueza pública, constituida en gran parte por la riqueza mineral; para el conocimiento del trazo y trayecto de las grandes líneas de ferrocarriles y para dar a conocer en Europa la minería, la geología y la paleontología mexicanas». Trabajos todos ellos, «importantes unos para el país; y nuevos otros para la ciencia» (ídem).

Con lo anterior, Del Castillo buscaba probar que la casa de la Dirección de Minería habitada por él, era «verdaderamente la oficina en que se están ejecutando con método, orden y con los objetos a la vista de colecciones ya ordenadas y clasificadas, ocupando los tres salones principales de la casa, que tienen la luz y el espacio que se sugieren para su estudio y revisión y para la ejecución de tales trabajos por su naturaleza misma» (AHPM,1882/ I/ 213/ doc. 66, f. 167).

Todo parece indicar que el proyecto contó con la venia de Carlos Pacheco, pues Del Castillo, como ingeniero en jefe, quedó facultado para elegir a dos de los ingenieros topógrafos ocupados en la formación de las cartas geográficas parciales, quienes levantarían las cartas geodésicas y topográficas y se encargarían de la formación de las carboníferas y geológico-mineras; tanto los sueldos y los gastos generados serían integrados en el presupuesto de las Escuelas de Ingenieros y Agricultura (ibídem, fs. 1v-2).

Del Castillo calculó las dotaciones del Cuerpo de Ingenieros del Instituto Geológico y los gastos de expedición en 4,000 pesos, de los cuales 2,800 pesos estarían destinados para los pagos del director ingeniero en jefe de las expediciones, que debía ser «minero, geólogo y paleontologista», dos ingenieros de minas geólogos, o geógrafos litologistas [sic] y mineralogistas, un ingeniero metalurgista, dos ingenieros topógrafos dibujantes para las cartas parciales a detalle, un dibujante y fotógrafo, un secretario contador y encargado de colectar y ordenar los datos de la estadística minera y 1, 200 pesos para los gastos de las expediciones. Estas asignaciones se reducirían a la mitad cuando se efectuaran los estudios de gabinete y la redacción de las memorias (ídem). Asimismo, en el proyecto se adjuntó una: calca de la carta de este género que comprende la parte austral metalífera de la Península de la Baja California y para dar una idea de las mismas que formarán el Atlas Paleontológico Mexicano se acompañó de dos láminas ya litografiadas de las familias de los perezosos y de los carniceros fósiles que componen parte de la fauna cuaternaria de los grandes valles de México, otra lámina, pero en dibujo, de la flora fósil más característica del terreno carbonífero de Tecomatlán y Olomatlán (Puebla) y otras seis también en dibujos de los fósiles, moluscos, característicos de la gran formación cretácea de San Juan de Raya en Puebla (ibídem, f. 2).

Algunos de estos trabajos fueron producto de la práctica de geología de 1881 realizada en la Escuela Nacional de Ingenieros dirigida por Del Castillo, entre los que se cita el Corte de N.O. a S.E. del Geyser de toba caliza, llamado Cuescomate: con desprendimiento intermitente de gas sulfídrico. Descubierto en 1881 por Antonio del Castillo en los suburbios de Puebla, Rancho de Posada, de una escala de 0.01 por 1 metro, que también contenía una vista tomada sobre el borde del géiser de S. a N., ubicado cerca de Puebla, entre el Batan y la hacienda de Posada. Del Castillo (1884) precisó que el «Cuescomate era un gran pilón hueco de toba caliza, sobresaliendo en la superficie del terreno con una cavidad elíptica subterránea en la base, y agua sulfúrea, con desprendimiento de gas sulfídrico. Probablemente es un antiguo respiradero de gases y aguas cargadas de bicarbonato de cal, depositando la toba a manera de Geyser» (Figura 2). También se elaboró el Plano de los pueblos de Cuatziyotla y Tepecatepetl, un corte geológico del Valle de Atlixco, Matamoros de Izúcar y terreno carbonífero de Ahuatlán, también en el estado de Puebla. De modo que las prácticas de campo fijaron como propósito formar colecciones de rocas y fósiles de todas las localidades recorridas, y recoger «los datos necesarios para la formación de un bosquejo de la Carta geológica de la República» (AHPM, 1881/ I/ 212/ doc. 1, f.1v).

Los quehaceres del Instituto Geológico al interior de la Escuela de Ingenieros caminaban acorde a los estudios llevados a cabo en el gabinete de mineralogía, geología y paleontología de la misma, que para esa fecha había enriquecido sus colecciones mediante la compra de una "colección general de todas las partes del mundo» al Dr. Krantz, de Bonn, Alemania, uno de los más afamados vendedores de minerales en el mundo, que complementó la colección de ejemplares de minerales del país y permitía «apreciar su mayor o menor importancia industrial» (AHPM, 1882/ IV/ 218/ 
doc. 26, s/f). En términos generales, los especímenes estaban ordenados con base a los caracteres externos dictados por Andrés Manuel del Río y la de especies mineralógicas por el sistema de James D. Dana (ídem).

Figura 2. Corte de N.O. á S.E. del Geyser de toba caliza, llamada Cuescomate: con desprendimiento intermitente de gas sulfrídico. Descubierto en 1881 por Antonio del Castillo, en los suburbios de Puebla, Rancho de Posada, escala 1: 100, blanco y negro, $59 \times 41 \mathrm{~cm}$

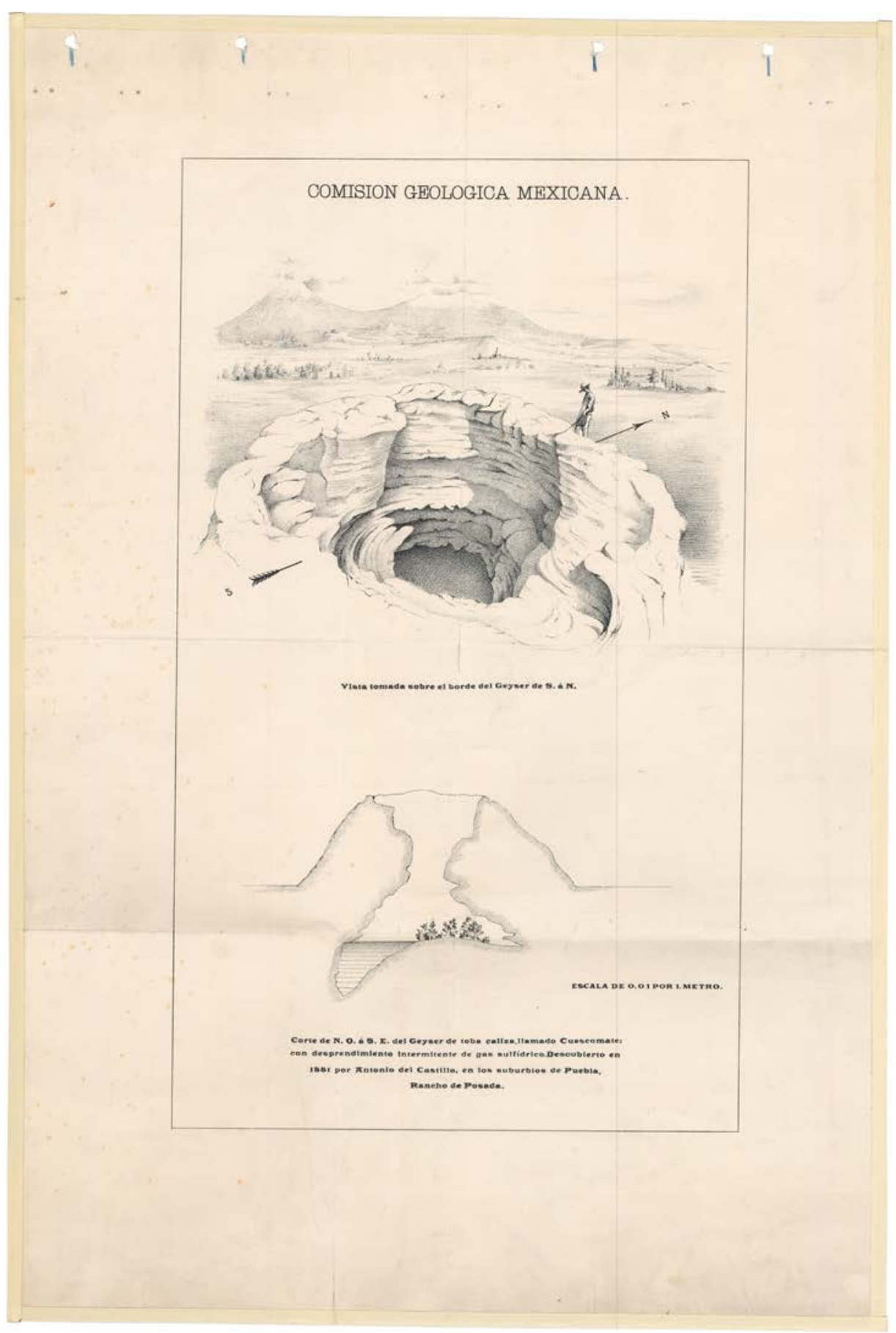

Fuente: Mapoteca "Manuel Orozco y Berra”, Servicio de Información Agroalimentaria y Pesquera, SAGARPA, Colección General, Estado de Puebla, varilla: CGPUE02, núm. 3908. 
Pese a los esfuerzos de Del Castillo y al apoyo de Pacheco, en junio de 1882 la Secretaría de Fomento preparaba su mudanza de la Cámara de Diputados al edificio de Minería precisamente en la casa del director (Morales, Monroy, 2013). En vista de ello, los materiales y objetos del Instituto Geológico se trasladaron en septiembre de ese año a "un salón que no tiene las condiciones que se necesitan para la continuación de los trabajos, y en él se acumularon los objetos en desorden» (AHPM, 1882/ II/ 213/ doc. 66, f. 168). Este cambio interrumpió de manera temporal las investigaciones científicas que había iniciado el Instituto bajo la guía de Antonio del Castillo.

A pesar de «la buena disposición en que se encuentra el C. Presidente para protegerlos, inspirado del interés con que ve dichos trabajos dirigidos de manera especial a la conclusión de un bosquejo de la Carta geológica del país» y los demás mapas, la fundación del Instituto implicaba, según el gobierno, la necesidad de estudiar con detenimiento el planteamiento, la reorganización y el personal que lo integraría, a través del estudio de los institutos geológicos europeos. Este argumento fue derivado de la depreciación de la plata, que había provocado una gran crisis monetaria y mercantil entre los años de 1883-1886 y ante ese escenario resultaba imposible sufragar un gasto de esa naturaleza (AHPM, 1882/IV/218/ doc. 1, f. 5v; Crisis, 1886).

Para octubre de 1883 surgió el proyectó para la creación de la Comisión Científica Mexicana bajo la dirección del célebre naturalista Alfonso Herrera (18381901), que fijaba como fines el establecimiento de un Instituto Geológico y de una Comisión Científica Central rectora de las exploraciones del territorio mexicano, existentes o futuras, bajo el punto de vista del estudio de la historia natural, arqueología, etnografía, lingüística, geología y de todo lo relativo a la flora, fauna y enfermedades reinantes.

La premisa de su organización era que «las naciones más civilizadas del mundo, sostienen perfectamente atendidos, establecimientos que pueden llamarse científicos-industriales, de la misma naturaleza que los proyectados». El modelo de las instituciones de Estados Unidos había demostrado su utilidad ya que "las grandes comisiones dirigidas por el centro que forman las cartas geológicas de los territorios federales y de los Estados, estudiando a la vez la zoología y la botánica de las diversas localidades», habían beneficiado a las industrias y a la sociedad (Pacheco, 1887).

Asimismo, se planteó la formación de la Carta geológica general de la República, las cartas geológico- mineras de los principales distritos mineros del país, acompañadas de las memorias respectivas sobre estadística minera, y la carta de los materiales de construcción más útiles e importantes; las cartas zoológicas, botánicas, agrícolas y médico-climatológicas y la publicación anual de una memoria de los estudios de cada departamento. Con estos dispositivos se podrían localizar importantes yacimientos y criaderos de minerales, materias primas para la construcción, desarrollar la industria minera, agrícola y la alfarería, cuya aplicación impactaría en las obras de ingeniería civil, disminuyendo los costos y los tiempos en su levantamiento. No obstante, el proyecto no prosperó (ídem).

Así pues, a la malograda iniciativa de 1882 que hiciera Del Castillo, le siguió otra cuatro años más tarde cuando el secretario de Fomento, general Pacheco presentó ante el Congreso de la Unión el 26 de mayo de 1886 una petición para fundar el Instituto Geológico. En su lugar se le concedió la formación de una Comisión Geológica Mexicana, de carácter temporal (Diario, 1888; Dublán, 1890; Aguilera, 1896; Gómez, 2005).

\section{LA COMISIÓN GEOLÓGICA MEXICANA Y SUS PROYECTOS}

Durante el primer tercio del siglo XIX, en los países más desarrollados económicamente y con vocación expansionista, se fundaron los primeros institutos geológicos (Geological Survey), dada la influencia de la Revolución Industrial que impulsó la búsqueda de minerales industriales y de fuentes de energía, tales como combustibles fósiles, carbón y petróleo, bajo el dominio del Estado. Este modelo institucional se replicó por todo el orbe y tuvo como objetivos centrales la generación de infraestructura para las ciencias geológicas, la realización de la cartografía orientada a la investigación de la riqueza mineral, de recursos geológicos y a la generación de informes expertos, precisos y asépticos (Guntau, 1978; Secord, 1986; Figueirôa, 1997; Calvo, 2008).

En este tenor, el presidente Díaz emitió el 17 de diciembre de 1888 el decreto de fundación del Instituto Geológico Nacional, aunque en sentido estricto continuó laborando la Comisión Geológica Mexicana. El precepto de ley establecía como fines del Instituto el estudio geológico del territorio nacional desde el punto de vista práctico, científico, técnico e industrial; formar y publicar la carta geológica de la República con su memoria respectiva; hacer y dar a conocer las cartas geológicas especiales y a detalle y estudios de regiones interesantes, especialmente de distritos mineros y montañas. Además, debía establecer y preservar un museo geológico de la nación, con las coleccio- 
nes clasificadas que sirvieran para la elaboración de las cartas y donde se pudieran ubicar los principales sitios mineros, entre otros datos. Por su naturaleza, el Instituto estaría unido a la Escuela Nacional de Ingenieros y a la Escuela Práctica de Minas y Metalurgia de Pachuca (AHPM, 1888/II/232, doc. 11, f. 2; Paredes, 1917; Santillán, 1933; Ordóñez, 1946; Enciso, 1988, 1989; Rubinovich, Mendoza, Lozano, 1998).

Su establecimiento iba aparejado al «consenso generalizado de las elites gobernantes sobre la conveniencia de promover el desarrollo de una industria nacional» (Beatty, 2003). Además, tanto las Secretarías de Hacienda y Fomento consideraban que la verdadera fuente de riqueza de México residía en sus recursos naturales, entre ellos los minerales y los productos agrícolas, a los que era necesario promover y buscar las rutas para su venta e inversión.

Los objetivos centrales de la Comisión Geológica Mexicana fueron la formación y la publicación de los mapas geológico y minero de la República Mexicana con sus respectivas memorias, hacer y difundir mapas geológicos especiales y estudios de regiones interesantes del país, como fallas, cañones, cuencas, volcanes, grutas y sobre los distritos mineros, que debían exhibirse en la Exposición Universal de París en 1889.

El Bosquejo de una Carta Geológica de la República Mexicana fue diseñado para dar una idea general de las formaciones geológicas dominantes en México y, al mismo tiempo, servir de base para el trabajo más perfecto y detallado que se ejecutaría posteriormente. Para su construcción, la Comisión Geológica adoptó como carta base la Carta General de la República Mexicana de 1863 de Antonio García Cubas publicada por la Secretaría de Fomento a la escala de tres millones; de ella se tomaron los contornos, las corrientes de agua y posición de los puntos principales de referencia que fueron necesarios para el levantamiento. Sobre ella se trazaron los límites de cada una de las formaciones principales del país (Aguilera, 1896) (Figura 3).

Figura 3. Bosquejo de una Carta Geológica de la República Mexicana (1889). Fuente: Bosquejo de una Carta Geológica de la República Mexicana (1889) elaborado por la Comisión Geológica de México, escala 1: 3,000,000, color, 81 x 111 cm. Imp. por Erhard Hermanos-París. Grabado por Erhard Hermanos 35 calle Denfert-Rochereau-París]

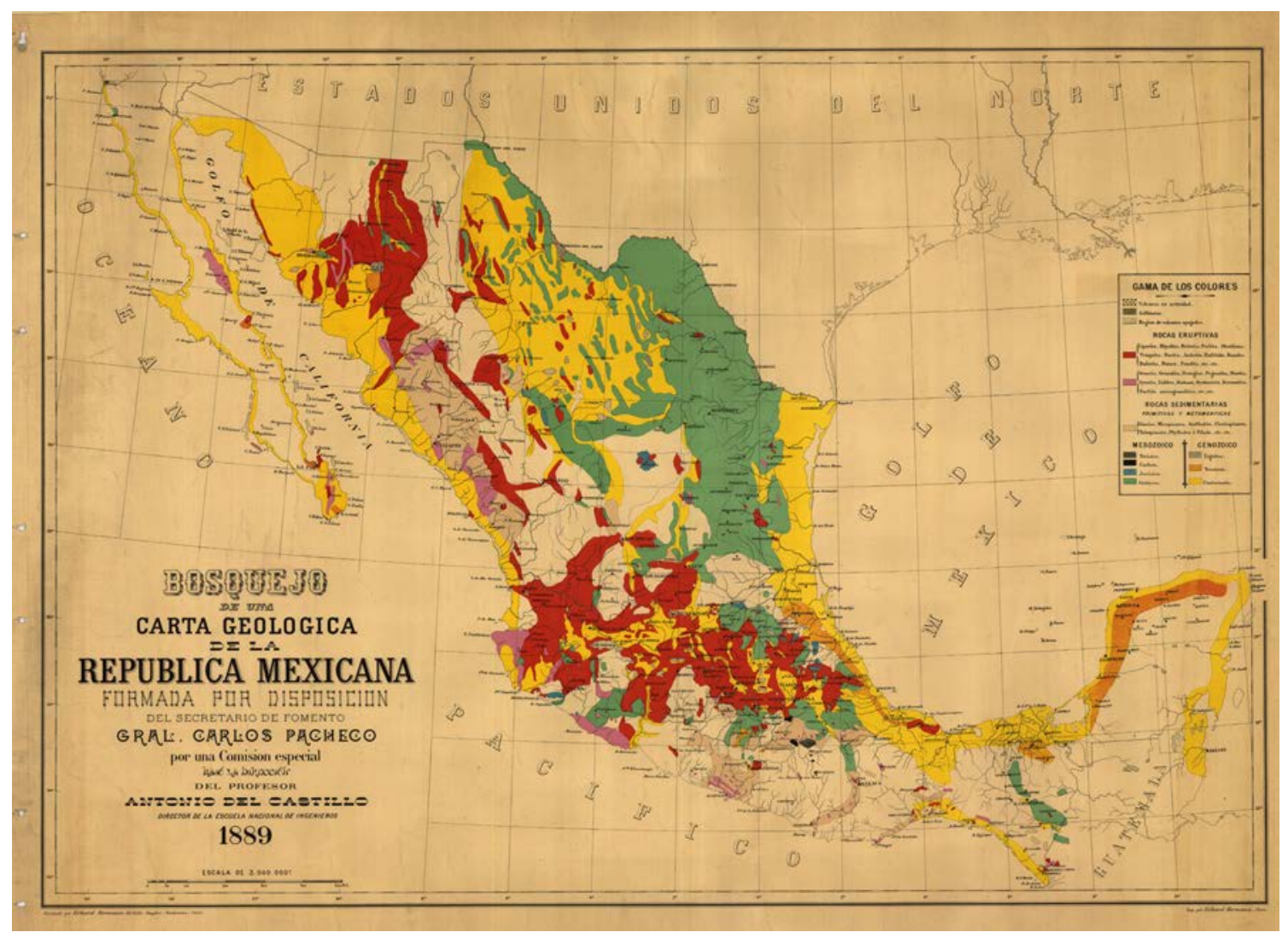

Fuente: Mapoteca «Manuel Orozco y Berra», Servicio de Información Agroalimentaria y Pesquera, SAGARPA, Colección General República Mexicana, varilla 5, núm. 7701. 
El Bosquejo fue la primera carta de su tipo en México y estuvo acompañada de un informe escrito con esmero, que enfatizaba en los planes y estudios geológicos de las regiones más interesantes del país, desde el punto de vista minero. Con la explicacion de sus colores, "servía tan sólo para juzgar la extensión e importancia relativa de cada una de las formaciones en él consignadas, pero no daba idea alguna de la naturaleza de sus rocas, su situación y posición actual, así como de su valor, desde el punto de vista industrial» (ídem). La Carta Minera de la República Mexicana buscaba mostrar la riqueza mineral que se guardaban en las entrañas de la tierra, atraer la inversión empresarial y elevar al máximo la explotación de los recursos naturales (Aguilera, 1905).

\section{EL PERSONAL DE LA COMISIÓN GEOLÓGICA MEXICANA}

La Comisión Geológica Mexicana estuvo integrada por un jefe o director, quien nombró a tres ingenieros topógrafos, dos dibujantes y paisajistas, dos geólogos auxiliares y un colector. Todos los integrantes de la Comisión provenían casi en su totalidad de la Escuela Nacional de Ingenieros y alguno más de la Escuela de Agricultura (véase Tabla I). El ingeniero Antonio del Castillo ostentaba el cargo de director y como era titular de la cátedra de mineralogía, geo- logía y paleontología, le fue concedida una licencia con goce de sueldo para ausentarse de las clases durante el tiempo que durara la comisión para el levantamiento de los trabajos a exhibirse en París, percibiendo un sueldo de 250 pesos mensuales (AHPM, 1888/ I/ 231/ doc. 6, ff. 4-5).

El cargo de geólogo fue ocupado por el ingeniero José Guadalupe Aguilera (1857-1941) (Figura 4), discípulo de Del Castillo en la Escuela de Ingenieros donde obtuvo el título de ensayador y apartador de metales y donde se desempeñó como conservador y preparador de los gabinetes de química analítica y aplicada (1880-1886) y mineralogía, geología y paleontología en 1882 (AHPM, 1882/ II/ 216/ doc. 2 , fs. 32-33). Al momento de su incorporación a la Comisión Geológica, en la que devengaría un sueldo de 200 pesos mensuales, laboraba como geólogo en la Comisión Científica de Sonora, tras una estancia en la Comisión Geográfico-Exploradora (1882-1884) como ingeniero geólogo y segundo naturalista, donde colaboró el general Victoriano Huerta. Este ingeniero llegaría a ocupar el cargo de director en el Instituto Geológico de México en dos periodos, de 1895 a 1912 y de 1914 a 1915 (Azuela, Morales, 2006; Cuevas, 2009).

Tabla I. Integrantes de la Comisión Geológica Mexicana (1888)

\begin{tabular}{lll}
\hline Fecha de nombramiento & Nombre & Categoría \\
\hline Marzo de 1888 & Antonio del Castillo & Director \\
\hline 12 de mayo de 1888 & José Guadalupe Aguilera & Geólogo \\
\hline 1 o de agosto de 1888 & Baltasar Muñoz & Geólogo \\
\hline 30 de abril de 1888 & Francisco Garibay & Topógrafo y configurador \\
\hline 20 de abril de 1888 & Lamberto Cabañas & Geólogo, Topógrafo y configurador \\
\hline 30 de abril de 1888 & Ezequiel Ordóñez & Ayudante de Geólogo y Dibujante \\
\hline 30 de mayo de 1888 & Juan Orozco y Berra & $\begin{array}{l}\text { Dibujante topógrafo e ingeniero encargado de la } \\
\text { conclusión final de las cartas topográficas }\end{array}$ \\
\hline 30 de abril de 1888 & Luis G. Becerril & Dibujante y Paisajista \\
\hline 8 de mayo de 1888 & Francisco Brito & Escribiente y coleccionador \\
\hline 14 de diciembre de 1888 & Juan Alonso & $\begin{array}{l}\text { Sustituto o interino de Francisco Brito como } \\
\text { Escribiente y coleccionador }\end{array}$ \\
\hline
\end{tabular}

Fuente: Morelos, 2012 
Figura 4. José Guadalupe Aguilera (1857-1941)

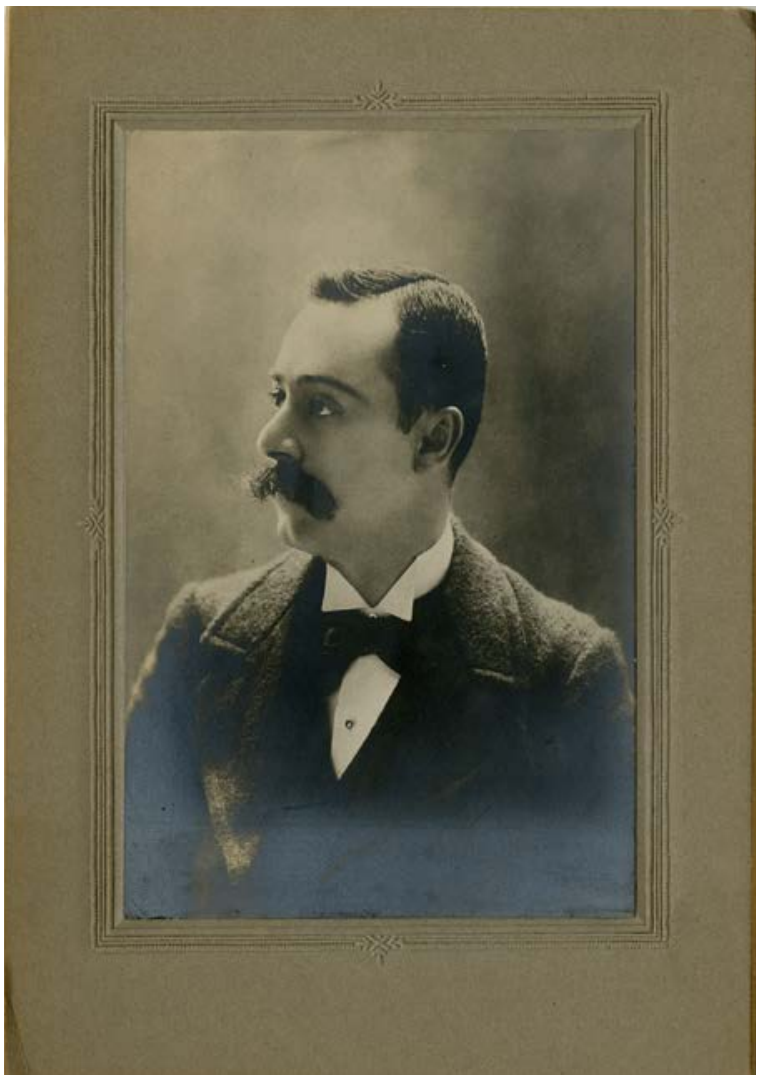

Fuente: AHPM, Colección Alzate, s/c.

Otro de los geólogos oficiales fue Baltasar Muñoz Lumbier (1856-1906) (Figura 5) quien obtuvo el título de ingeniero de minas en la Escuela Nacional de Ingenieros en 1878, al tiempo que se le nombró preparador de la clase de química analítica y aplicada (AHPM, 1879/ I/ 208/ doc. 9, f. 2).

Francisco Garibay, al momento de su nombramiento en la Comisión era titular del gabinete de topografía y mecánica industrial en la Escuela Nacional de Ingenieros y para 1890 obtuvo el título de ingeniero topógrafo hidrógrafo (AHPM, ML 301 A, f. 75). Lamberto Cabañas, fue un ingeniero agrónomo egresado de la Escuela Nacional de Agricultura en 1885, a quien se le nombró geólogo, topógrafo y configurador (Figuras 6 y 7 ).

Ezequiel Ordóñez Aguilar (1867-1950) y Luis Gonzaga Becerril Carrillo se desempeñaron como dibujantes paisajistas donde percibieron un sueldo de 240 pesos mensuales. Al momento de su nombramiento, Ordóñez ocupaba el cargo de conservador del gabinete de geología y mineralogía en la Escuela de Ingenieros (Figura 8). En junio de 1890 fue nombrado catedrático interino
Figura 5. Baltasar Muñoz Lumbier (1856-1906)

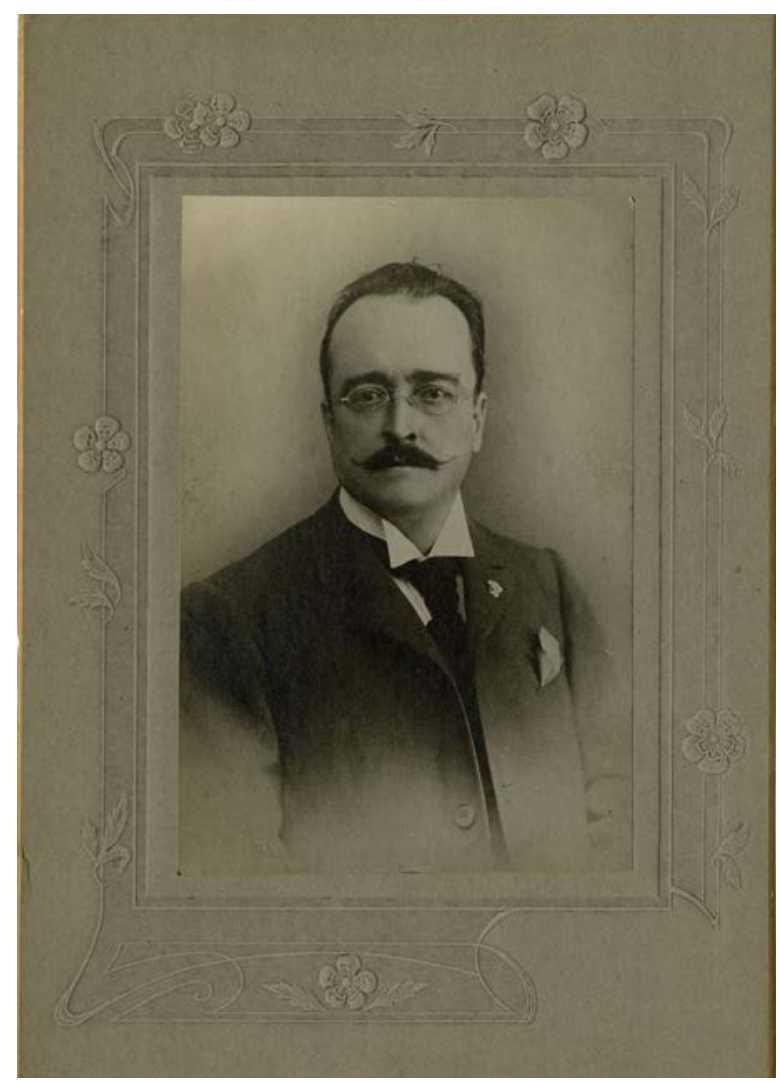

Fuente: AHPM, Colección Alzate, s/c.

de mineralogía, geología y paleontología y responsable de la práctica de campo (Rubinovich, Mendoza, Lozano, 1998). Obtuvo el título de ingeniero topógrafo e hidrógrafo el 23 de mayo de 1893. Mientras que Becerril era bibliotecario de la Escuela de Ingenieros y yerno de Antonio del Castillo (Morelos, 2014).

Francisco Brito fue nombrado escribiente y coleccionador de la comisión, donde percibió un sueldo de 120 pesos mensuales. Ocupaba el cargo de mozo práctico de los gabinetes de mineralogía, geología y paleontología y materiales de construcción (ídem). Para el cargo de escribiente y coleccionador interino se nombró a Juan Alonso con el sueldo de 120 pesos mensuales y para el cargo de dibujante topógrafo a Juan Orozco y Berra con un sueldo de 300 pesos mensuales. Este personaje obtuvo el título de ensayador y apartador en 1881 en la Escuela de Ingenieros, fue pionero en la sismología en México e hijo del historiador y geógrafo Manuel Orozco y Berra (1816-1881). Por desgracia se suicidó en agosto de 1890, luego de haber salido de prisión a causa de una riña con un albañil, a quien había dado muerte (Figura 9). 
Figura 6. Francisco Garibay

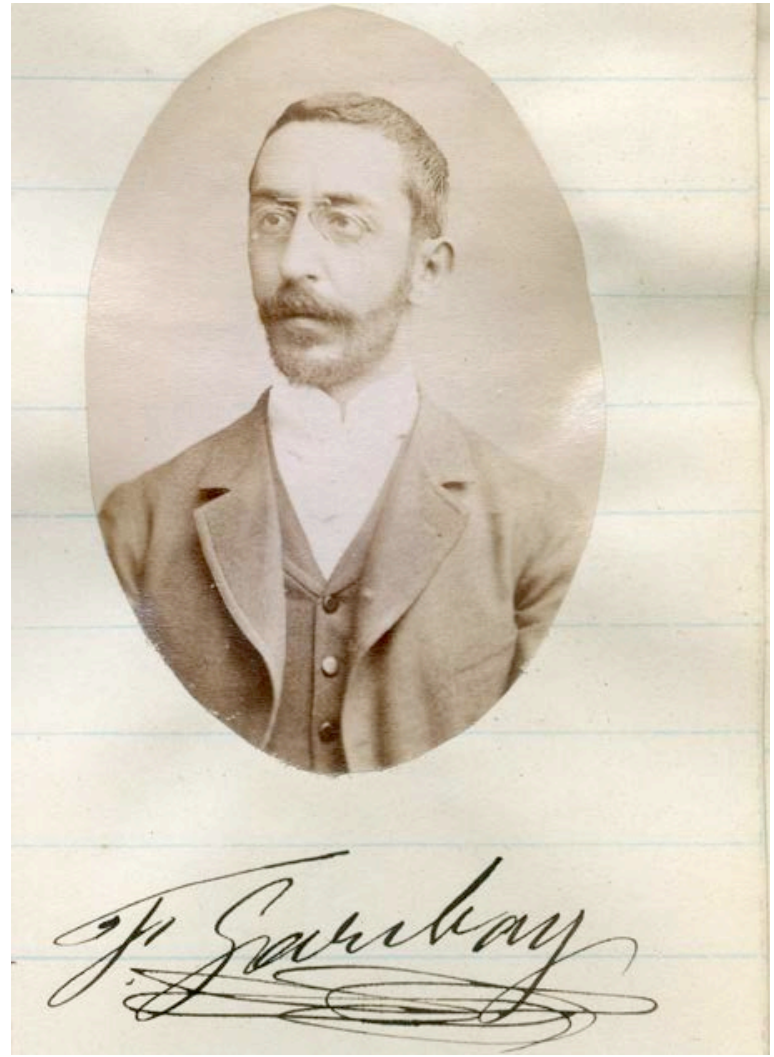

Fuente: AHPM, ML 301 A, f. 75.

Figura 7. Lamberto Cabañas

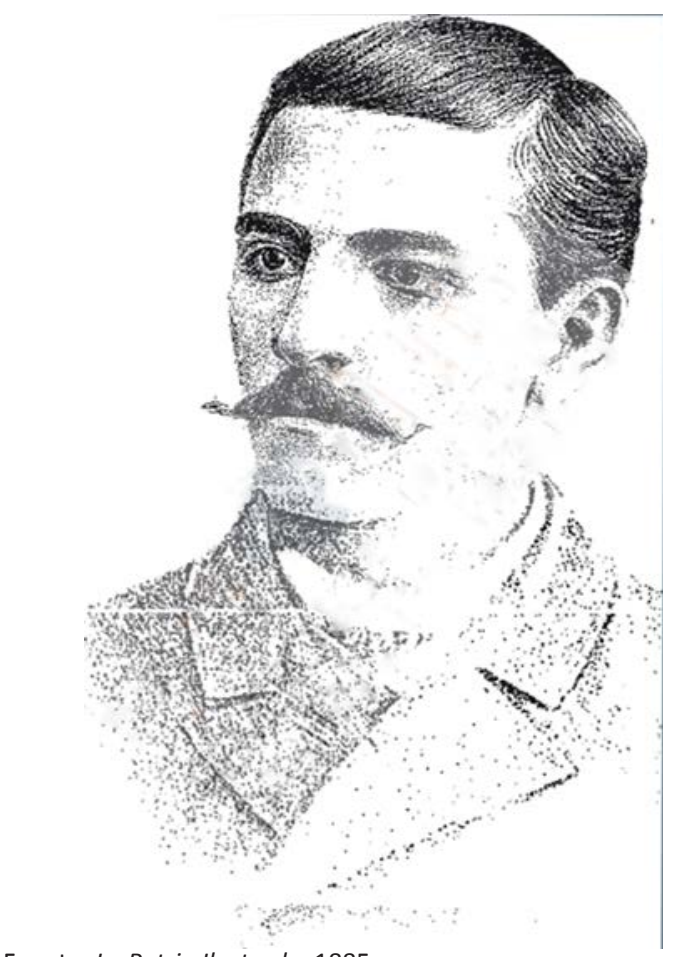

Fuente: La Patria Ilustrada, 1885.
Figura 8. Ezequiel Ordóñez (1867-1950)

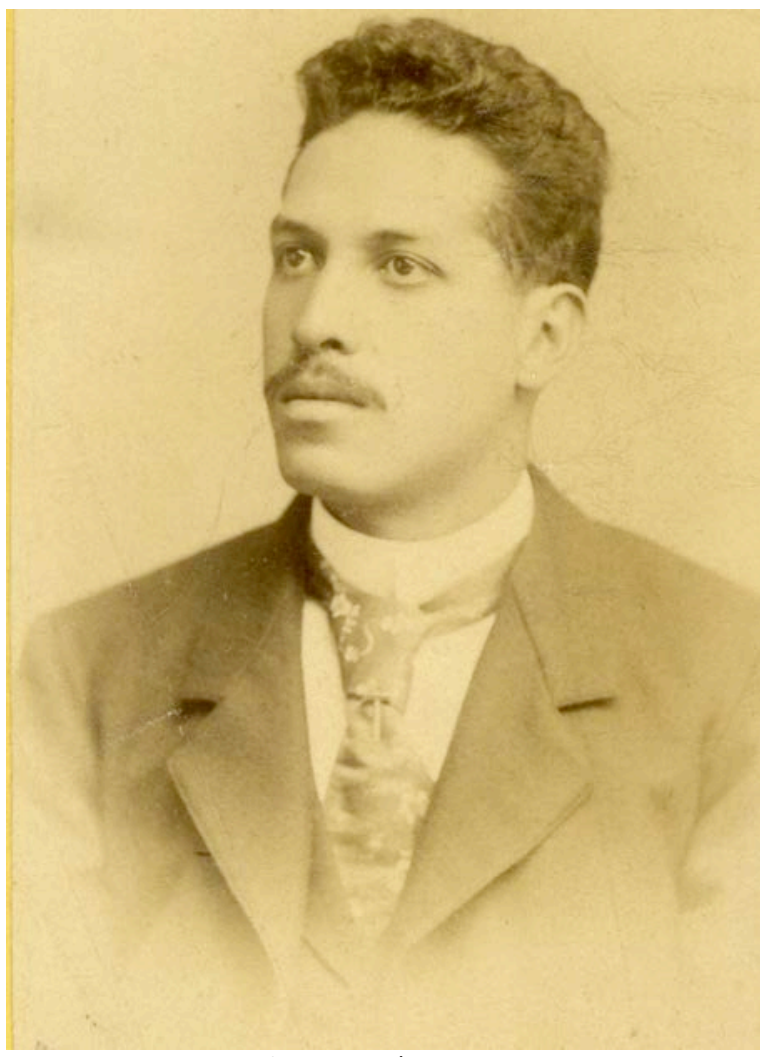

Fuente: AHPM, Colección Alzate, s/c.

Figura 9. Juan Orozco y Berra ( $\dot{c}-1890)$

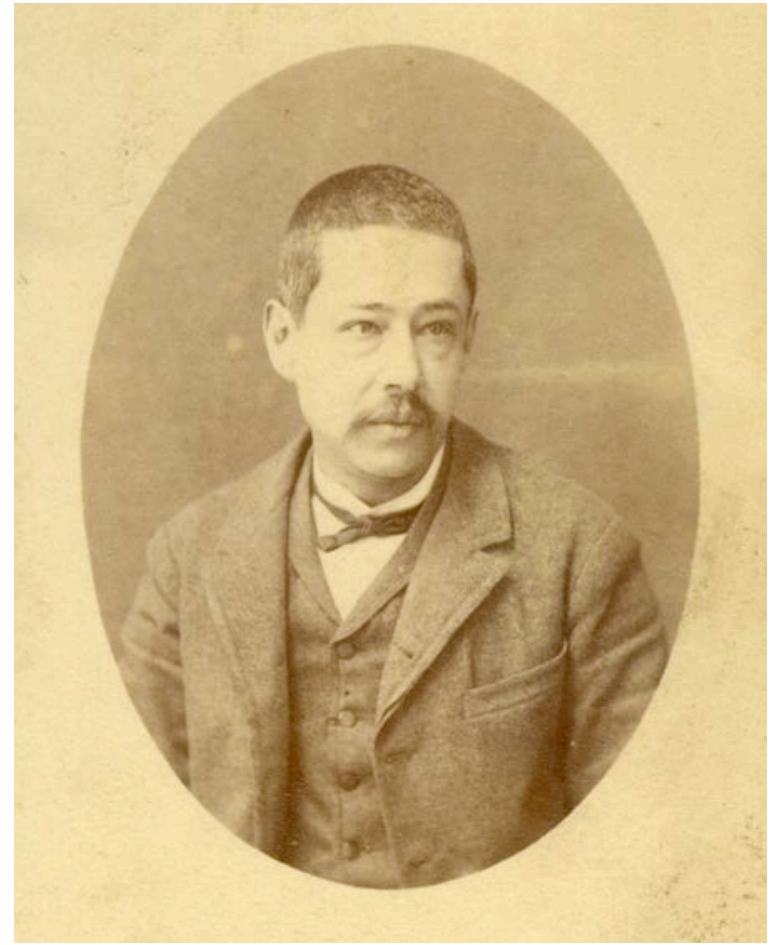

Fuente: AHPM, Colección Alzate, s/c. 
Como geólogo auxiliar se nombró a Joaquín Lorenzana Rivero, quien obtuvo los títulos de ensayador y apartador de metales en 1874 y el de ingeniero de minas en 1878, también en la Escuela de Ingenieros y luego de su participación en la Comisión se dedicó a realizar trabajos para particulares en Zacatecas, donde se distinguió en la política hasta 1894, cuando falleció.

Además, la nómina de personal incluyó a los inspectores de minas y al geólogo de la Comisión Geográfico-Exploradora con sus dependientes. Para la ejecución de los trabajos, el Ministerio de Fomento y la Escuela de Ingenieros facilitaron la información contenida en sus archivos, referente a las expediciones científicas que precedieron a la Comisión Geológica, notas informativas, mapas y perfiles y las colecciones de rocas. Además se dispuso de los fondos sobrantes del presupuesto de Escuela, con el fin de que iniciara sus tareas en tanto se le otorgaba una partida propia por la Secretaría (AHPM, 1888/ I/ 231/ doc. 6, f. 24).

La sede de la Comisión fueron tres salones de la Escuela Nacional de Ingenieros donde instalaron los diversos departamentos de trabajo de gabinete y las colecciones que ocuparían durante seis meses, tiempo de duración de la comisión. Para la ejecución de los trabajos, el Ministerio de Fomento y la Escuela facilitaron los instrumentos y aparatos, tales como termómetros de diversos tipos, microscopios, balanzas y herramientas (AHPM, 1897/ III/ 259/ doc. 16, fs. 2-3; AHUNAM, ENI/ caja 18/ doc. 10, f. 64).

Mientras se preparaban las cartas geológica y minera en México, Del Castillo y el ingeniero Jorge L. Rivero viajaron a Europa para asistir al IV Congreso Geológico Internacional en Londres en 1888, sesión en la que se eligieron a diversas personalidades del mundo científico para iniciar los trabajos de la comisión internacional relativa a la nomenclatura, la determinación de los nombres, la extensión de las divisiones y los colores que debían adoptarse en el mapa geológico de Europa; entre ellas se encontraba el ingeniero Del Castillo, en calidad de vicepresidente (Rivero, 1892).

La Comisión deliberó la unificación de colores y figuras que acompañarían las cartas; no obstante, fue hasta la $5^{\text {a }}$ sesión del Congreso Geológico Internacional en Washington en 1891, cuando finalmente se homologó la gama de colores de las rocas fosilíferas, aunque la escala de colores propuesta para uniformar ese tipo de trabajos de manera incipiente databa de 1882, cuando se celebró el segundo Congreso Geológico Internacional en Bolonia.
Para la representación de las rocas fosilíferas en las cartas se estipuló que para el periodo Neoceno $(N)$ se usaría el color naranja; para el Eoceno (E), amarillo; el Cretáceo (K) amarillo-verde; el Jura Trías [sic] (J), azulverde; el Carbonífero (C), azul; el Devónico (D), violeta; el Silúrico $(S)$, púrpura; el Cámbrico $(\Theta)$, rosa y para el Algonquino (A), rojo. Respecto a las rocas eruptivas, dominantes en el suelo mexicano, se adoptaron los colores, rojo y rosa, para designar las dos grandes series (Congrès, 1893; Aguilera, 1896).

Durante su estancia en Europa, los ingenieros mexicanos visitaron diversos establecimientos científicos, estudiaron su organización, las publicaciones, el desarrollo de las ciencias, las colecciones y fue allí donde Del Castillo se percató del interés que merecían los meteoritos, de los que México contaba con dos de las más grandes masas de fierro en el mundo, Chupaderos I y II. Fue entonces cuando pidió autorización al gobierno mexicano para presentar además de los trabajos en preparación, un inventario de los meteoritos conocidos en México.

De esa manera se exhibió en Paris el Catalogue descriptif des Météorites (Fers et Pierres Météoriques) du Mexique avec l'indication des localités dans lesquelles ces météorites sont tombés ou ont été decouverts (1889), el cual estuvo acompañado de doce moldes en papel maché que mostraban sus dimensiones reales (Morelos, 2013). Fue tal el interés que despertaron, que los moldes fueron obsequiados al Museo de Historia Natural de París, y el destacado mineralogista vienés Aristides Brezina (1848-1909) coordinó la réplica para el Museo de Historia Natural de Viena, a cargo del escultor Johann Mayerhofer, para después ser copiadas en papel maché por $\mathrm{M}$. Henstchel y fotografiadas por Hermann Bell (Ritter, 1891). Por su parte, el profesor de geología del museo parisino Auguste Daubrée (1889), publicó una reseña sobre los trabajos presentados por Del Castillo en 1889, en la que afirmó que México junto con los Estados Unidos y Chile se citaban entre los países más dotados de las masas de fierro meteóricas encontradas en el mundo.

A su regreso a México, los comisionados ordenaron los materiales que se presentarían en Europa. De regreso a París, Del Castillo ordenó la impresión de un millar de ejemplares del bosquejo geológico y otro tanto del mapa minero, bajo el cuidado de la casa Erhard, reconocida por la reciente edición que había hecho de la Carte géologique de la France dirigida por Ferdinand Fouqué y Michel Lévy, para su posterior distribución en el mundo científico (AGN, Fomento/ Exposiciones Extranjeras/ caja 1/ doc. 16, f. 88v) ${ }^{6}$. 
El total de trabajos elaborados por la Comisión Geológica fue de 22, mismos que constituyeron la base para la formación del Bosquejo de una Carta Geológica de la República; quedaron compilados en un $\mathrm{Ca}$ tálogo que fue terminado en el mes de abril de 1889. Se dividieron en tres grupos: cartas y planos, planos topográficos y vistas y paisajes geológicos. Dentro del primer grupo se levantaron el Bosquejo de una Carta General Geológica de la República, el Plano geológico de los criaderos de fierro de la Ferrería de la Encarnación, el Plano geológico del Peñón de los Baños donde se encontró el hombre fósil prehistórico, el Plano geológico de la extremidad Sur de la Sierrita de Guadalupe con criaderos de Hafta (sic) y surtido de gas carbónico, el Plano geológico de una parte oriental de la Sierrita de Guadalupe y la Carta general Minera de la República Mexicana (ídem).

Por su parte, los planos topográficos elaborados por los comisionados fueron: Plano de la Sierra mineral de Techachalco en que están las minas Preciosa y Huchá con las Maaras del rededor, Plano de los crátereslagos de los Distritos de San Andrés Chalchicomula, Estado de Puebla, Plano de los criaderos de fierro magnético de la Ferrería de la Encarnación, Distrito de Zimapán, Estado de Hidalgo, Plano de Texalucan (colinas con restos de plantas fósiles fucoideas y el Plano de la región en que han caído los Meteoritos más notables de México con tres reproducciones por el procedimiento de Nigrosina.

En cuanto a las vistas y paisaje geológicos, éstos comprendieron un «Atlas de los paisajes y maaras de Alchichica, San Miguel Tecuitlapa, paisaje de Texaluca, cañada Morelos, del geiser de toba caliza llamado Cuescomate en la Hacienda de Posada, maara de Alxoxuca, maara "La Preciosa", maara Quecholaca, Atexcaqui y Xalapasco». Las vistas al óleo fueron sobre los cráteres apagados entre la Hacienda de San Nicolás y San Isidro, de los cráteres de volcanes apagados de San Nicolás Xaltepec y Santa Catarina, de la cadena y montañas volcánicas al norte de la Hacienda de San Isidro, una vista al temple de la cadena de cráteres de volcanes apagados desde Santa Catarina a San Nicolás, una vista de la caldera (cráter de volcán apagado) cerca de la Hacienda de San Isidro, una vista al lápiz del cerro del Convento (criadero aurífero) en Tetela del Oro, una vista del Cerro de Ometepec al E. de Tetela del Oro (pizarra caliza con amonitas), la vista de una capa metalífera en la entrada a la labor de la mina del Teposan (criaderos de capas metalíferas estratificadas), de estratificación discordante de capas de pizarra en un corte del Ferrocarril
Central Km. 72, Tula, vista de un corte natural de basalto en lajas y otra del Cerro del Peñón de los Baños en el Valle de México (ídem).

El jefe de la Comisión Geológica Mexicana además tenía la encomienda de «abrir un mercado provechoso para las minas de México, dando salida a sus productos de poco valor pero, muy abundantes, de algunos de sus distritos minerales próximos a las líneas de ferrocarriles o a sus costas», entre ellos los metales de zinc y plomo (ídem) y realizar el estudio práctico de las maquinarias y herramientas modernas para abrir pozos artesianos a "grandes diámetros", para utilizarlos en la inauguración de los trabajos prácticos de los ingenieros del Instituto Geológico de México «para la investigación de ello o capas de agua subterráneas brotantes, con objeto de proporcionar aguas de irrigación a los vastos y estériles suelos de los estados del norte», y también para que dichas maquinarias y herramientas pudieran servir en la investigación de las fuentes de gases naturales para combustible y alumbrado, «que en estos últimos tiempos se ha alcanzado en los Estados Unidos del Norte con grandes ferrerías y economía de alumbrado de ese país (ídem; AHPM, 1889/ II/ 234/ doc. 5, fs. 5-9).

\section{FUNDAMENTOS PARA LA CONSTRUCCIÓN DEL BOS- QUEJO DE LA CARTA GEOLÓGICA Y MINERA DE MÉXICO}

La obra fundamental para la ejecución del Bosquejo de la Carta Geológica fue el Tratado de Geología de Albert de Lapparent, con el objeto de seguir la clasificación de Ferdinand Fouqué y Michel Lévy contenida en la Minéralogie micrographique. Roches éruptives françaises (1879); con su publicación quedó manifiesta la importancia que la aplicación del microscopio tenía para el estudio de los elementos constitutivos de las rocas cristalinas (Fouqué, Levy, 1879).

También se utilizaron las colecciones de rocas y fósiles clasificadas y ordenadas hasta 1887 por José G. Aguilera en los Museos de Mineralogía y Geología de la Escuela Nacional de Ingenieros, haciéndose necesaria la revisión y reclasificación de acuerdo a los preceptos de Lapparent. Para ello -escribe Aguilera-:

me serví de las localidades de los ejemplares para situarlos sobre la Carta, unida a las Cartas de las formaciones geológicas de los estados de Puebla, Tlaxcala, Oaxaca, Sonora y Veracruz, formados por el que suscribre, los que constituyeron el núcleo de los conocimientos de la geología del suelo mexicano, reduciendose así a menores proporciones los trabajos de campo que tenían necesidad de llevar 
a cabo para conseguir la representación en la Carta de más de un 50 por ciento de la superficie del país (Aguilera, 1896).

Igualmente se aprovechó la cartografía, literatura científica, libros, tratados, artículos, reportes técnicos e informes de las comisiones de exploración resguardados en los archivos de la Secretaría de Fomento y la Escuela Nacional de Ingenieros. Se hizo uso de los itinerarios recorridos por el ingeniero José G. Aguilera cuando ocupó el cargo de ingeniero geólogo y segundo naturalista en la Comisión Geográfico-Exploradora, entre los años de 1882 a 1884, que cubrían porciones de los estados de Puebla, Veracruz, Tlaxcala, Oaxaca y Sonora, así como la Carta de Durango formada por el célebre Antonio García Cubas. También se emplearon la Colección de Informes Geológicos (1870) formados por el ingeniero Mariano Bárcena, las cartas topográficas de las Comisiones de Límites entre México y Guatemala y los mapas de la Comisión GeográficoExploradora. Además, el ingeniero Del Castillo, acompañado de Ordóñez y Cabañas, realizaron algunas expediciones a algunos de los principales minerales del Estado de México e Hidalgo; el director y Aguilera visitaron algunos otros del estado de Querétaro. A Baltasar Muñoz Lumbier se le confió la exploración del estado de Chihuahua, la parte meridional de Sinaloa y la meridional de Sonora, y a Aguilera los estados de Coahuila, Nuevo León, Tamaulipas, Veracruz y la parte oriental de San Luis Potosí y Durango (ídem).

\section{EL INSTITUTO GEOLÓGICO NACIONAL Y EL PERFEC- CIONAMIENTO DE LA CARTA GEOLÓGICA DE MÉXICO}

Los conocimientos mineros y geológicos fueron de gran interés para el presidente de la República, general Porfirio Díaz, pues el 22 de marzo de 1891 viajó al sur del país donde visitó algunos parajes del estado de Morelos y el mineral de Huitzuco en Guerrero, en compañía de Antonio del Castillo, el Secretario de Gobernación Manuel Romero Rubio y el senador Rosendo Pineda. A su regreso, el primer magistrado dispuso que el 15 de abril de 1891 se reinstalara la Comisión Geológica, «que más tarde sería reemplazada por la creación de un Instituto bien organizado", para perfeccionar los espacios en blanco del Bosquejo de la Carta Geológica de la República Mexicana (1889) para exhibirla en la Exposición de Chicago de 1893, a mayor escala y con notables correcciones. Fueron ratificados Aguilera, Muñoz, Ordóñez, Cabañas, Becerril y Del Castillo, a quien en ese mismo mes el gobierno francés le confirió la Cruz de Caballero de la Orden de la Legión de Honor.
(AHUNAM, Instituto de Geología/ caja 22/ exp. 204, f. 34; Anónimo, 1891a; Anónimo, 1891b).

Con el fin de perfeccionar el mapa se organizó una expedición geológica minera a la sierra del Estado de México, cuyo itineario rebasó las 120 leguas [500km. aproximadamente] y quedó integrada por los ingenieros Antonio del Castillo y Lamberto Cabañas, para «recorrer y explorar una considerable serranía comprendida entre el mineral de Sultepec, Julúapan, El Cristo, Tlataya, el nuevo criadero de azogue de San Juan Amajaque, extendiéndose hasta Tiscaltepec y Xochicalco (minas de Agua Zarca), frente al cerro del Gallo, donde la serranía está interrumpida por la cuenca del gran río de las Balsas o Mexcala» (Castillo, 1891).

En esta expedición se estudiaron las rocas que componían esa extensión de terreno en su parte metalífera, que formaban un espacio en blanco de la carta geológica, y «que se ha llenado de rocas dominantes de la serranía, denominadas pizarras cristalinas, de gran interés para la ciencia pues su génesis u origen y época de antigüedad geológico» fue debatido en el Congreso Geológico Internacional en Londres, quedando abierta la discusión para la sesión en Washington en agosto de 1891, a la cual acudió Del Castillo y contribuyó con su hallazgo (ídem).

Aparte del estudio geológico se hizo el de sus minerales, en particular el de un nuevo criadero de azogue en la Cuadrilla de San Juan Amajaque, del que se desprendió que dicho criadero «era enteramente distinto de todos los demás de la República, y por su carácter de antigüedad geológica de la roca en que arma, parece ocupar una época de formación más antigua» (ídem). El mineral era de cinabrio oscuro y bien podría llegar a ser un rico yacimiento comparable con los de mayor producción del Viejo y Nuevo Almadén, en España y Alta California, respectivamente. Con su descubrimiento se podría bajar el precio del azogue y la minería mexicana tendría por consiguiente un aumento en su producción, pues el precio del metal fluctuaba con gran facilidad, lo que hacía más costoso el procedimiento de beneficio. Es decir, el resultado útil de esta expedición fue doble, por un lado contribuyó a las ciencias y desde el punto de vista industrial, ubicó un yacimiento mercurial para el beneficio metalúrgico (Anónimo, 1891c).

Las ediciones al mapa geológico obligaron, como es natural, a perfeccionar y completar datos mediante el cotejo en la práctica de campo y la consulta de artículos y obras de reciente publicación. Las adiciones y correcciones de datos completaron las no- 
ticias que se tenían sobre los distritos mineros, los meteoritos, la estratigrafía del terreno y orden de las rocas, la distribución geográfica de los depósitos de petróleo, chapopote y carbón, la fauna característica de las diversas edades, los fenómenos volcánicos, las principales elevaciones y sus alturas, los materiales de construcción y objetos diversos, las aguas sulfurosas o curativas y los datos petrográficos. También se detalló el territorio mexicano y se determinó su edad, de acuerdo a la Carta Estratigráfica internacional vigente en ese momento.

Con la formación de la Carta Geológica de México, por primera vez se pudo apreciar en un solo documento la cobertura general de las distintas formaciones rocosas del país y las áreas donde se desconocía en su totalidad la constitución geológica (Castillo, 1891). Después se elaboraron nuevas ediciones entre 1891 a 1896, haciéndose más completa y a menor escala, a 1: 1000000 .

En suma, la importancia de la construcción del primer mapa geológico general de México es que mostraba ya la nomenclatura, la determinación de los nombres, la extensión de las divisiones y los colores que debían adoptarse en el mapa geológico de Europa que se estaba elaborando, y que habían sido presentados en el IV Congreso Geológico Internacional, celebrado en Londres en 1888. Permitió tener un amplio conocimiento sobre las formaciones dominantes en el territorio y sus subdivisiones, proporcionó nuevos datos sobre la descripción y clasificación de las rocas, facilitó conocer la génesis de los yacimientos que las contienen y deducir indicaciones sobre la probable distribución de la riqueza mineral.

Pero, además, inspiró la elaboración de otros mapas de gran interés, como fueron la Carta estadística minera de la República Mexicana y la Carta de los meteoritos de México, ambas de 1893, productos novedosos para la industria minera y para el desarrollo de las ciencias geológicas y sus especialidades. En palabras del ingeniero Gilberto Crespo y Martínez (1891):

[...] vasto campo de investigaciones se presentará al Instituto, y tendrá material suficiente para redactar memorias interesantísimas, pero nosotros quisiéramos ver que el principal objeto de sus trabajos fuera el estudio detenido de los minerales ya conocidos en la República. El estudio geológico de nuestro territorio, un fin puramente especulativo es de recomendarse, la ciencia podrá adquirir nuevos descubrimientos y hallar numerosas comprobaciones de sus leyes, pero este estudio puramente especulativo, es propio de los países que se encuentran en su pleno desarrollo y que son ricos. Distintos fines deben perseguirse en este plantel, pues ante todo deben estudiarse con escrupulosidad los Distritos mineros que se trabajan, tanto para dar a conocer su verdadera importancia y porvenir, como porque en ellos el estudio será más sencillo [...].

El Bosquejo de una Carta geológica, la Carta Minera de la República Mexicana y demás planos fueron valorados por la prensa capitalina y extranjera como trabajos útiles, por haber procedido «de la manera que lo hacen los grandes oficiales facultativos de estado mayor que comienzan primero por formar cartas estratégicas al 1/500,000 o al 1/320,000 para gradualmente llegar a hacer cartas tácticas al 1/60,000 o al 1/50,000 para venir por último a formar cartas de detalle a 1/10,000. México ya tiene su Carta Geológica; le falta ahora completar este bosquejo», como indicó Alberto Samson, redactor de El Minero Mexicano (Anónimo, 1893).

\section{A MANERA DE CONCLUSIÓN}

La geología y sus representaciones gráficas modernas surgieron como una práctica profesional por parte de los ingenieros formados en el Colegio de Minería, después Escuela Nacional de Ingenieros y luego Comisión Geológica Mexicana. En estos espacios, los ingenieros científicos contribuyeron al inventario de los recursos naturales y minerales de México, por medio de textos e informes y de una importante labor en la representación gráfica del territorio que finalizó en un gran proyecto de construir la carta geológica de la República.

Aunque fueron numerosos los actores que a lo largo de la primera mitad del siglo antepasado elaboraron mapas que ahora podemos calificar como aportaciones al conocimiento geológico de México, se tuvo que esperar hasta la segunda mitad para que, con apoyo del gobierno federal se estableciera una Comisión Geológica Mexicana (1888) que tuvo como objetivos formar la carta geológica de la República y hacer cartas geológicas de regiones interesantes, como distritos mineros y montañas.

Pero más importante, estas primeras cartas generales mostraban ya la nomenclatura, la determinación de los nombres, la extensión de las divisiones y los colores que debían adoptarse en el mapa geológico de Europa que se estaba elaborando. El trabajo se perfeccionó con base en nuevas exploraciones por todo el territorio, la incorporación de estudios sobre el país elaborados por científicos extranjeros y los nuevos desarrollos teóricos de la disciplina. 
La creación del Instituto Geológico de México significó un gran avance en el campo del desarrollo científico pues impulsó la entrada de nuevos temas como la petrología, la meteorítica o bien, promovió el cultivo de otras especialidades como la paleontología. Además, los ingenieros científicos legitimaron su quehacer mediante el pago remunerado de su trabajo, el reconocimiento como expertos en cierta especialidad y la certificación de los saberes. Representaron una minoría de la elite científica porfiriana, pues sus trabajos fueron de naturaleza aplicada que aspiraba a tener resultados. En tanto geólogos oficiales, debían producir estudios, acumular conocimiento normalizado y seguir instrucciones o protocolos estandarizados, como parte de las instituciones públicas bajo la custodia del Estado.

\section{NOTAS}

1 Carl de Berghes estudió ingeniería, geometría y geodesia en la Universidad de Aquisgrán. Después de 1815 se unió a una Compañía Minera Germano-Americana dedicada a la exploración minera en México y posteriormente trabajó para una compañía inglesa.

2 Boletín Mensual de la Oficina de las Repúblicas Americanas (1899), vol. II (5), noviembre, Unión Internacional de Repúblicas Americanas.

3 La publicación insertó dos planos y dos mapas, uno geológico con perfiles, que mostraba información general de las rocas con la indicación de los depósitos minerales en México, publicado por dos eminentes mineralogistas, Frederick von Gerolt y Carl de Berghes, producto de sus viajes por México y otro mapa topográfico compilado por este último. Igualmente incluyó algunas vistas del Valle de México de la autoría del célebre viajero y pintor alemán Johann Moritz Rugendas (1802-1858).

\section{FUENTES PRIMARIAS}

Archivo General de la Nación (AGN).

Acervo Histórico del Palacio de Minería (AHPM).

\section{BIBLIOGRAFÍA}

Aguilera, José G. (1896), "Prólogo”, Bosquejo Geológico de México, Boletín 4-6, México, Instituto Geológico de México, pp. 11-15.

Aguilera, José G. (1905), “Reseña del desarrollo de la Geología en México", Boletín de la Sociedad Geológica Mexicana, 1a época, tomo I (35), México, pp. 35-117.
En el lapso de 1881 a 1891 se ubican los orígenes y puesta en marcha del Instituto Geológico de México, que evidenció el enlace entre las políticas públicas y las iniciativas personales de los hombres de ciencia. Este proyecto permitió a Antonio del Castillo y sus colegas entrar en contacto directo con los pobladores de las comarcas que recorrieron, conocer el suelo mexicano y legitimar su posición como expertos en los ámbitos local e internacional. Asimismo, la construcción de las cartas evidenció cuan inexplorado se encontraba el país en las postrimerías del siglo XIX, pero también expresó de manera implícita que la modernización de los caminos a través del ferrocarril hacía posible transitarlo y llevar a cabo empresas científicas y económicas.

4 El baron de Gerolt fue encargado de los negocios de Prusia en la Ciudad de México desde 1840 hasta 1845, y después embajador del rey de Prusia en Washington durante el periodo de 1846 a 1871 . Fue muy amigo de Alexander von Humboldt y fomentó correspondencia con muchos naturalistas e historiadores de América.

5 Originalmente esta comisión inició labores en septiembre de 1856 para la formación del "Atlas nacional, que comprende la historia y la geografía antiguas, la arqueología, la zoología, la botánica, la estadística y las cartas geológicas y geodésicotopográficas del Valle de México". Paralizó su actividad en 1857 debido a la guerra entre conservadores y liberales.

6 El presupuesto de gastos para la impresión de los trabajos de la Comisión Geológica por parte de E. Erhard fue de 5, 241 francos. El grabado de la Carta minera costó 900 francos, el de la Carta geológica 1, 250 francos; el grabado del plano geológico de la Encarnación 195 francos y el plano geológico del Peñón de los Baños, 175.

Archivo Histórico de la Universidad Nacional Autónoma de México (AHUNAM).

Aguilar y Santillán, Rafael (1908), "Bibliografía geológica y minera de la República Mexicana", Boletín del Instituto Geológico de México 17, México, Imprenta y Fototipia de la Secretaría de Fomento.

Anónimo (1891), "El Señor Presidente de la República", El Siglo Diez y Nueve, año 50, tomo 99 (15952), 23 de marzo, México, p. 3. 
Anónimo (1891), "Comisión Geológica", El Siglo Diez y Nueve, año 50, tomo 99 (15975), 18 de abril, México, p. 3.

Anónimo (1891), "Los trabajos de la Comisión Geológica Mexicana", Revista Minera e Industrial, Económica, Administrativa, Social, Artística y de Viajes, vol. IV, núm. 22, 1 de julio, México, p. 256.

Anónimo (1893), "La Carta Geológica de la República”, El Minero Mexicano, tomo XXIII, núm. 7, 17 de agosto, México, p. 81.

Azuela, Luz Fernanda y Rafael Guevara Fefer (1998), "La ciencia en México en el siglo XIX: una aproximación historiográfica", Asclepio. Revista de Historia de la Medicina y de la Ciencia, Madrid, CSIC, 50 (2), pp. 77-105.

Azuela, Luz Fernanda y Claudia Morales (2006), "La reorganización de la geografía de la geografía en México en 1914: crisis institucional y resignificación de la práctica", Scripta Nova. Revista electrónica de geografía y ciencia sociales, Universidad de Barcelona, 10 (218).

Barnes, Barry (1987), Sobre ciencia. Barcelona, Editorial Labor, $150 \mathrm{p}$.

Beatty, Edward (2003), "Visiones del futuro: la reorientación de la política económica en México, 1867-1893", Signos Históricos, núm. 10, julio-diciembre, México, pp. 38-56.

Bernstein, Marvin D. (1964), The Mexican Mining Industry 1890-1950. A study of the Interaction of Politics, Economics, and Technology. New York, State University, 412 p.

Blanco, Mireya y José Omar Moncada (2011), “El Ministerio de Fomento, impulsor del estudio y el reconocimiento del territorio y el reconocimiento del territorio mexicano (18771898), Investigaciones Geográficas, Boletín del Instituto de Geografía", UNAM, núm. 74, México, pp. 74-91.

Bowler, Peter J. (1998), Historia fontana de las ciencias ambientales. México, Fondo de Cultura Económica, 467 p.

Brianta, Donata (2000), "Education and Training in the Mining Industry, 1750-1860: European Models and the Italian Case", Annals of Science, 57 (3), pp. 267-300.

Burkart, Joseph (1836), Aufenthal und Reisen in Mexico in den Jahren 1825 bis 1834, Bemerkugen über Land, Produkte, Leben und Sitten der Einwohner und Beobachtungen aus dem Gebiete der Mineralogie, Geognosie, Bergbaukunde, Meteorologie, Geographic, 2 vol. Stuttgard, Schweizerbart.

Calvo, José Pedro (2008), “Contribución de los Servicios Geológicos al desarrollo de las Ciencias de la Tierra", Enseñanza de las ciencias de la tierra: Revista de la Asociación Española para la Enseñanza de las Ciencias de la Tierra, 16 (1), pp. 17-22.

Castillo, Antonio del (1843), “Ojeada sobre algunos conocimientos útiles al minero", El Siglo Diez y Nueve, año II, núm. 686, segunda época, México, 12 de septiembre, p. 3.
Castillo, Antonio del (1868), Discurso pronunciado en la distribución de premios a los alumnos del Colegio Nacional de Minería por el profesor de Mineralogía y Geología. México, Imprenta del Gobierno, en Palacio.

Castillo, Antonio del (1870), "Discurso pronunciado por el señor ingeniero de minas D. Antonio del Castillo, Presidente de la Sociedad, en la sesión inaugural verificada el día 6 de septiembre de 1868", La Naturaleza. Periódico científico de la Sociedad de la Sociedad Mexicana de Historia Natural, tomo I, años de 1869 y 1870, México, pp. 1-5.

Castillo, Antonio del (1884), Informe que rinde el Director de la Escuela N. de Ingenieros correspondiente al año de 1882. México, Oficina Tipográfica de la Secretaría de Fomento, $46 \mathrm{p}$.

Castillo, Antonio del (1891), "Ciencias", El Minero Mexicano, tomo XVIII (24), 16 de julio, México, p. 280.

Congrès Géologique International, Compte Rendu de la 5 me Session, Washington 1891 (1893), Washington, Imprimerie du Gouvernement, 529 p.

Corona, Pedro y José Alfredo Uribe (2009), Atlas cartográfico del distrito minero El Oro-Tlalpujahua. Morelia, Michoacán, Universidad Michocana de San Nicolás de Hidalgo, Consejo Estatal de Ciencia y Tecnología, Gobierno del Estado de Michoacán, 103 p.

Crespo y Martínez, Gilberto (1891), "Instituto Geológico”, Revista Minera e Industrial, vol. IV (6), 5 de febrero, México, p. 63.

Cuevas Cardona, Consuelo (2009), “Estudios naturalistas de la Secretaría de Fomento: la Sección de Historia Natural de la Comisión Geográfico-Exploradora de México (1882-1915). En: Lértora Mendoza, Celina (coord.), Geografía e Historia Natural: hacia una historia comparada. Estudio a través de Argentina, México, Costa Rica y Paraguay, Buenos Aires, Ediciones FEPAI, pp. 159-178.

La crisis monetaria. Estudios sobre la crisis mercantil y la depreciación de la plata hechos por acuerdo del Sr. Presidente de la República en virtud de la iniciativa de la Secretaría de Fomento, Colonización, Industria y Comercio (1886). México, Oficina Tipográfica de la Secretaría de Fomento.

Daubrée, Auguste (1889), “Note de M. Daubrée accompagnant la présentation d'un Catalogue descriptif des météorites du Mexique, rédigé par M. Antonio del Castillo", Comptes Rendus Hebdomadaires des Séances de L'Académie des Sciences, tomo CIX (20), 11 Novembre, Paris, Gauthier-Villars et Fils, Imprimeurs-Libraires, pp. 725-727.

Diario Oficial del Supremo Gobierno de los Estados Unidos Mexicanos (1888), tomo XIX, núm. 152, 25 de diciembre. México, p. 2.

Dublán, Manuel y José María Lozano (1876-1912), Legislación Mexicana o Colección completa de las disposiciones legis- 
lativas expedidas desde la Independencia de la República Mexicana ordenada por los licenciados. México, edición oficial, Imprenta y Litografía de Eduardo Dublán y Comp., 52 vols.

Egloffstein, Baron F.W. von (1864), Contributions to the Geology and the Physical Geography of Mexico, including a geological and topographical map, with profiles, of some of the principal Mining Districts; together with a graphic description of an ascent of the Volcano Popocatepetl. New York, D. Appeton \& Company, $40 \mathrm{p}$.

Enciso de la Vega, Salvador (1988), "Creación y evolución del Instituto de Geología de la UNAM", Ciencia y desarrollo, 14 (81), julio-agosto, México, Consejo Nacional de Ciencia y Tecnología, pp. 41-47.

Enciso de la Vega, Salvador (1989), "El Instituto de Geología de la UNAM y algunos de sus antecedentes históricos", Geomimet, 16 (160), julio-agosto, México, pp. 17-32.

Escamilla González, Francisco Omar (2005), "Ilustración alemana y ciencia novohispana: la Biblioteca de Fausto de Elhúyar". En: Horst Pietschmann, Manuel Ramos Medina, María Crisitina Torales Pacheco (edit.), Alemania y México: percepciones mutuas en impresos, siglos XVI-XVIII, Cátedra Guillermo y Alejandro de Humboldt, México, Universidad Iberoamericana, pp. 399-475.

Escamilla González, Francisco Omar (2011), “¿Orictognosia o mineralogía: la influencia de Abraham Gottlob Werner en el Real Seminario de Minería de México". En: Gobierno del Estado de México (ed.), Plata forjando México. México, Biblioteca Mexiquense del Bicentenario, pp. 526-561.

Fernández Leal, Manuel (1878), "Informe sobre el reconocimiento del Istmo de Tehuantepec presentado al gobierno mexicano por el ingeniero topógrafo y jefe de la Comisión que practicó el reconocimiento [mayo 30 de 1874]", Anales del Ministerio de Fomento de la República Mexicana, tomo III, México, Ministerio de Fomento, Colonización e Industria, F. Díaz de León, pp. 185-307.

Fernández Leal, Manuel (1879), Informe sobre el reconocimiento del istmo de Tehuantepec presentado al gobierno mexicano. México, Imprenta de Francisco Díaz de León.

Figueirôa, Silvia (1997), As ciências geológicas no Brasil: Uma história social e institucional, 1875-1934. Sâo Paulo, Editora Hucitec, $270 \mathrm{p}$

Flores Clair, Eduardo (2000), Minería, educación y sociedad. El Colegio de Minería, 1774-1821, Colección Científica. México, INAH.

Fouqué, Ferdinand y Michel Lévy (1879), Memoires pour servir a l'explication de la carte géologique détaillée de la France. Mineralogie micrographique. Roches éruptives francaises. Paris, Imprimerie de A. Quantin.
Garay, José de (1844), Reconocimiento del Istmo de Tehuantepec practicado en los años 1842 y 1843, con el objeto de una comunicación oceánica, por la Comisión Científica que nombró al efecto el empresario D. José de Garay. México, Imprenta de Vicente García Torres, 40 p.

García de León, Porfirio (1993), “En búsqueda de una imagen para el México del siglo XIX". En: Escandón, Patricia y Azuela, Luz Fernanda (coord.), Historia del quehacer científico en América Latina, México, UNAM, Coordinación de Humanidades, pp. 57-73.

Gerolt, Friedrick von, Agente y C. de Berghes, Ingeniero Mecánico de la Compañía Minera Alemana (1828), Carta Geognóstica de los principales Distritos Minerales del Estado de México formada sobre las Observaciones Astronómicas Barométricas y Mineralógicas, Año de 1827, Litografía de Arnz y Co., en Dúfseldorf.

Gómez Caballero, Arturo (2005), "Historia e índice comentado del Boletín del Instituto de Geología de la UNAM", Boletín de la Sociedad Geológica Mexicana, volumen conmemorativo del centenario. Aspectos históricos de la geología en México, tomo LVII (2), México, pp. 149-185.

González Casanovas, Ignacio, Alonso Serena Fernández, William W. Culver, Cornel J. Reinhardt, Julio Pinto Vallejos, Steven S. Volk, Inés Herrera Canales, Rina Ortiz Peralta, Cuauhtémoc Velasco Ávila (1994), Minería americana y colonial y del siglo XIX, Colección Científica. México, INAH, 174 p.

Guntau, Martin (1978), "The emergence of Geology as a scientific discipline", History of Science, vol. XVI, pp. 280-290.

Hallam, Anthony (2008), "Neptunistas, vulcanistas y plutonistas". En: Llorente, Jorge, Ruiz, Rosaura, Zamudio, Graciela y Noguera, Ricardo (comp.), Fundamentos históricos de la Biología, México, UNAM, Secretaría de Desarrollo Institucional, Dirección General de Publicaciones y Fomento Editorial, Facultad de Ciencias, pp. 243-270.

Ibarra Escobar, Guillermo; Ana Luz Ruelas y Arturo Carrillo Rojas (1994), Culiacán a través de los siglos. Culiacán, Universidad Autónoma de Sinaloa, Escuela de Historia.

Izquierdo, José Joaquín (1958), La primera casa de las ciencias en México: el Real Seminario de Minería, 1792-1811. México, Ciencia.

Klein, Ursula (2012), "Artisanal-scientific Experts in Eighteenthcentury France and Germany", Annals of Science, 69 (3), Julio, pp. 303-306.

López Monroy, Pedro (1878), “Exploraciones geológicas", El Minero Mexicano, tomo VI (5), 31 de octubre, México, pp. 49-51.

Lundgreen, Peter (1990), “Engineering Education in Europe and the U.S.A., 1750-1930: The Rise to Dominance of School Culture and the Engineering Professions", Annals of Science, 47 (3), pp. 33-75. 
Maldonado Koerdell, Manuel (1952), "Naturalistas extranjeros en México", Historia Mexicana, 2 (1), julio-septiembre, México, El Colegio de México, pp. 98-109.

Maldonado Koerdell, Manuel (1964), "La Commission Scientifique du Mexique, 1864-1869". En: Beltrán, Enrique (ed.), Memorias del Primer Coloquio Mexicano de Historia de la Ciencia, México, Sociedad Mexicana de Historia de la Ciencia y la Tecnología, pp. 239-247.

Marcou, Jules y John Belknap Marcou (1884), “Mapoteca geológica americana. A catalogue of Geological Maps of America (North and South), 1752-1881. In Geographic and chronologic order", Bulletin of the United States Geological Survey, no. 7, Washington, Government Printing Office, 184 p.

Mentz, Brígida von (1980), "Tecnología minera alemana en México durante la primera mitad del siglo XIX", Estudios de Historia Moderna y Contemporánea de México, UNAM, Instituto de Investigaciones Históricas, vol. 8, pp. 85-95.

Mentz, Brígida von, Verena Radkau; Beatriz Scharrer y Guillermo Turner (1982), Los pioneros del imperialismo alemán en México. México, CIESAS, Ediciones de la Casa Chata.

Moncada, José Omar (2003), El nacimiento de una disciplina: la geografía en México (siglos XVI-XIX), Temas Selectos de Geografía de México, I.1.6..México, UNAM, Instituto de Geografía, 131 p.

Morales Rodríguez Leopoldo y Virginia Guzmán Monroy (2013) "Intervenciones constructivas en la Escuela Nacional de Ingenieros: 1860-1890". En: Escamilla, Francisco Omar (coord.), 200 años del Palacio de Minería. Su historia a partir de fuentes documentales, México, UNAM, Facultad de Ingeniería, pp. 314-363.

Morelos Rodríguez, Lucero (2012), La geología mexicana en el siglo XIX. Una revisión histórica de la obra de Antonio del Castillo, Santiago Ramírez y Mariano Bárcena. México, Plaza y Valdés, Secretaría de Cultura de Michoacán, 356 p.

Morelos Rodríguez, Lucero (2013), "Las piedras del cielo de la Escuela Nacional de Ingenieros: 1893". En: Escamilla, Francisco Omar (coord.), 200 años del Palacio de Minería. Su historia a partir de fuentes documentales, México, UNAM, Facultad de Ingeniería, pp. 450-493.

Morelos Rodríguez, Lucero (2014), Historia de las ciencias geológicas en México. De entidad gubernamental a instituto universitario (1886-1929), Tesis inédita de doctorado en Historia. México UNAM, Facultad de Filosofía y Letras, 327 p.

Moro, Cayetano (1844), "Reconocimiento del istmo de Tehuantepec. Practicado en los años 1842 y 1843, con objeto de una comunicación oceánica, por la comisión científica que nombró el empresario D. José de Garay", El Ateneo Mexicano, tomo I, México, pp. 321-357.

Ritter von Hauer, Franz (1891), "Notizen”, Annalen des K. K. Naturhistorischen Hofmuseums, Band VI, Viena, pp. 27-31.
Olea, Héctor R. (1975), Ecología descriptiva de Sinaloa. México, Sociedad Mexicana de Geografía y Estadística, 201 p.

Ordóñez, Ezequiel (1946), El Instituto de Geología. Datos históricos. México, UNAM, Instituto de Geología, 102 p.

Orozco y Berra, Manuel (1864), Memoria para la Carta Hidrográfica del Valle de México formada por acuerdo de la Sociedad Mexicana de Geografía y Estadística. México, Imprenta de A. Boix.

Orozco y Berra, Manuel (1871), Materiales para una cartografía mexicana, Sociedad de Geografía y Estadística. México, Imprenta del Gobierno.

Orozco y Berra, Manuel (1881), Apuntes para la historia de la geografía en México. México, Imprenta de Francisco Díaz de León.

Pacheco, Carlos (1887), Memoria presentada al Congreso de la Unión por el Secretario de Estado y del Despacho de Fomento, Colonización, Industria y Comercio de la República Mexicana, corresponde a los años transcurridos de enero de 1883 a junio de 1885, 5 vols. México, Oficina Tipográfica de la Secretaría de Fomento.

Paredes, Trinidad (1917), "El Instituto Geológico Nacional", Boletín Minero, tomo IV (5), 1 de noviembre, México, pp. 471-486.

Pelayo, Francisco (1991), Las Teorías geológicas y paleontológicas durante el siglo XIX. Madrid, Ediciones Akal, Historia de la Ciencia y de la Técnica.

Ramírez, Santiago (1875), "Discurso en elogio fúnebre del Dr. H. José Burkart, pronunciado en la sesión que la Sociedad Mexicana de Geografía y Estadística celebró en honor de este sabio, por el socio honorario ingeniero de minas, el día 15 de mayo de 1875", El Propagador Industrial, 1 (9), 12 de junio, México, pp. 98-102.

Ramírez, Santiago (1890), Datos para la historia del Colegio de Minería. México, Imprenta del Gobierno Federal en el ex Arzobispado.

Rivero, Joaquín L. (1892), “Descripción de la Cuarta Reunión del Congreso Internacional Geológico, en Londres, en Setiembre de 1888, por un miembro del mismo", Anales de la Asociación de Ingenieros y Arquitectos de México, tomo III, México, Oficina Tipográfica de la Secretaría de Fomento, pp. 20-28.

Robles Pezuela, Luis (1866), Memoria presentada a S.M. el Emperador por el Ministro de Fomento, de los trabajos ejecutados en el ramo el año de 1865. México, Imprenta de J.M. Andrade y F. Escalante.

Rowan, Steve (2012), The Baron in the Grand Canyon. Columbia, University of Missouri Press.

Rubinovich Kogan, Raúl (1992), "Andrés Manuel del Río y sus Elementos de Orictognosia de 1795-1805", introducción a la 
edición facsimilar de A. M. del Río, Elementos de Orictognosia 1795-1805. México, UNAM, pp. 3-70.

Rubinovich Kogan, Raúl; Héctor Mendoza y María Lozano (1998), Ezequiel Ordóñez Aguilar. Vida y obra (1867-1950), vol. 1. México, Colegio Nacional, Instituto de Geología, 315 p.

Salazar Salinas, Leopoldo (1923), “Discurso pronunciado por el Ingeniero L. Salazar Salinas, en la velada que el Instituto Geológico de México organizó en honor del Ingeniero D. Antonio del Castillo, fundador y primer director del Servicio Geológico de México", Revista Mexicana de Ingeniería y Arquitectura. Órgano oficial de la Asociación de Ingenieros y Arquitectos de México, 1 (7), 15 de septiembre, México, Empresa Editorial de Ingeniería y Arquitectura, pp. 436-442.

Saldaña, Juan José y Luz Fernanda Azuela (1996), “De amateurs a profesionales. Las sociedades científicas en México en el siglo XIX", Quipu. Revista Latinoamericana de Historia de las Ciencias y la Tecnología, 11 (2), México, pp. 135-171.

Santillán, Manuel (1933), Anuario del Instituto de Geología 1932, Universidad Nacional Autónoma de México. México, Editorial Cultura, p. 162. p.

Secord, James A. (1986), "The Geological Survey of Great Britain as a Research School, 1839-1855", History of Science, vol. 24, pp. 223-275.

Shufeldt, Robert W. (1872), Reports of Explorations and Surveys, to ascertain the practicability of a ship-canal between the Atlantic and Pacific Oceans, by the way of the Isthmus of Tehuantepec by Captain United States Navy. Washington, Government Printing Office, p. 151 p.

Soberanis, Alberto (1995), "La ciencia marcha bajo la égida de la guerra. Las relaciones científicas franco-mexicanas durante el Imperio de Maximiliano (1864-1867)", Revista Universidad de Guadalajara, enero-febrero, pp. 50-60.

Uribe Salas, José Alfredo (2006), “Labor de Andrés Manuel del Río en México: profesor en el Real Seminario de Minería e innovador tecnológico en minas y ferrerías", Asclepio. Revis- ta de Historia de la Medicina y de la Ciencia, vol. LVIII, no. 2 julio-diciembre, pp. 231-260.

Uribe Salas, José Alfredo (2013), "De la aclimatación de la mineralogía al desarrollo de la geología o la promoción de conocimientos para el desarrollo de México, siglo XIX". En: Calvo, Luis; Álvaro Girón y Miguel Ángel Puig Samper (eds.), Naturaleza y laboratorio, Barcelona, Residència d'Investigadors, CSIC-Generalitat de Catalunya, pp. 117-142.

Velasco Ávila, Cuauhtémoc; Eduardo Flores Clair; Alma Parra Campos y Edgar O. Gutiérrez (1988), Estado y Minería en México (1767-1910). México, Fondo de Cultura Económica, 455 p.

Villegas Revueltas, Silvestre (2005), “Expansión del comercio mundial y estrategias de fomento al comercio durante el gobierno de Manuel González, 1880-1884", Revista de Estudios de Historia Moderna y Contemporánea de México, vol. 29, UNAM, México, Instituto de Investigaciones Históricas, México, pp. 41-92.

Weidner, Federico (1858), El Cerro de Mercado de Durango o Compendio de noticias mineralógicas, geognósticas, históricas, estadísticas y metalúrgicas del dicho cerro y la ferrería de San Francisco, México, Imp. de Andrade y Escalante, 34 p.

Weidner, Federico (1882), Statistical and Geological Notes accompanying the Map of Sinaloa. San Francisco, Francis, Valentine \& Co., Printers and Endgraves, 19 p.

Weidner, Federico (1884), "Der mexicanische Staat Sinaloa", A. Petermanns, Mitteilungen aus Justus Perthe's Geographischer Anstalt, Gotha, vol. 30, pp. 1-9.

Wehrheim, Monika (2010), "En búsqueda de una historia regional: Carl de Berghes y su descripción de las ruinas de La Quemada (1855)", Revista de Humanidades: Tecnológico de Monterrey, 27-28, México, Instituto Tecnológico y de Estudios Superiores de Monterrey, pp. 379-391.

Zittel, Karl A. (1901), History of Geology and Palaentology. To the End of the Nineteenth Century. London, Walter Scott, Paternoster Square, Charles Scribner's Sons, pp. 46-48. 